OPEN ACCESS

Edited by:

Petro Starokadomskyy,

University of Texas Southwestern

Medical Center, United States

Reviewed by:

Tengchuan Jin,

University of Science and Technology

of China, China

Marina Gottikh,

Lomonosov Moscow State University,

Russia

${ }^{*}$ Correspondence:

Hongyan Sui

suih@mail.nih.gov

Tomozumi Imamichi

timamichi@mail.nih.gov

Specialty section:

This article was submitted to

Microbes and Innate Immunity,

a section of the journal

Frontiers in Cellular

and Infection Microbiology

Received: 20 August 2021 Accepted: 06 October 2021 Published: 21 October 2021

Citation:

Sui $H$, Hao $M$, Chang $W$ and Imamichi T (2021) The Role of Ku70 as a Cytosolic DNA Sensor

in Innate Immunity and Beyond.

Front. Cell. Infect. Microbiol. 11:761983.

doi: 10.3389/fcimb.2021.761983

\section{The Role of Ku70 as a Cytosolic DNA Sensor in Innate Immunity and Beyond}

\author{
Hongyan Sui ${ }^{*}$, Ming Hao, Weizhong Chang and Tomozumi Imamichi * \\ Laboratory of Human Retrovirology and Immunoinformatics, Frederick National Laboratory for Cancer Research, Frederick, \\ MD, United States
}

Human Ku70 is a well-known endogenous nuclear protein involved in the non-homologous end joining pathway to repair double-stranded breaks in DNA. However, Ku70 has been studied in multiple contexts and grown into a multifunctional protein. In addition to the extensive functional study of Ku70 in DNA repair process, many studies have emphasized the role of Ku70 in various other cellular processes, including apoptosis, aging, and HIV replication. In this review, we focus on discussing the role of Ku70 in inducing interferons and proinflammatory cytokines as a cytosolic DNA sensor. We explored the unique structure of Ku70 binding with DNA; illustrated, with evidence, how Ku70, as a nuclear protein, responds to extracellular DNA stimulation; and summarized the mechanisms of the Ku70-involved innate immune response pathway. Finally, we discussed several new strategies to modulate Ku70-mediated innate immune response and highlighted some potential physiological insights based on the role of Ku70 in innate immunity.

Keywords: Ku70, Ku heterodimer, cytosolic DNA sensing, innate immunity, interferons, HIV replication

\section{INTRODUCTION}

Innate immunity includes diverse areas of host defense response to pathogen invasion, such as bacterial or viral infection. In this system, pattern recognition receptors (PRRs) expressed in host cells recognize the conserved pathogen-associated molecular patterns (PAMPs) which are derived from microbes and then mediate innate immune responses (Medzhitov and Janeway, 1997; Medzhitov and Janeway, 2000; Akira et al., 2006; Pichlmair and Reis e Sousa, 2007; Mogensen, 2009; Takeuchi and Akira, 2009; Yoneyama and Fujita, 2010). Detection of pathogenic cytosolic

\footnotetext{
Abbreviations: DNA-PK, DNA-dependent protein kinase; NHEJ, non-homologous end-joining; PRRs, pattern recognition receptors; PAMPs, pathogen-associated molecular patterns; TLRs, Toll-like receptors; RIG-I, retinoic acid-inducible gene I; NF- $\mathrm{KB}$, nuclear factor $\mathrm{\kappa B}$; IFN, interferon; IRF3, Interferon regulatory factor 3; IL-1 $\beta$, interleukin-1 $\beta$ b; DDX41, DEAD-box helicase 41; IFI16, gamma-interferon-inducible protein; DAI, DNA-dependent activator of IFN-regulatory factors; dsDNAs, double-stranded DNAs; LRRFIP1, Leucine-rich repeat flightless-interacting protein 1; DHX, DEAH box protein; AIM2, absent in melanoma 2; PYHIN, pyrin- and HIN200-domain-containing protein; MyD88, myeloid differentiation primary response 88; cGAS, cyclic GMP-AMP synthase; ASC, apoptosis-associated speck-like protein; XRCC, X-ray repair cross-complementing protein; NLS, nuclear localization signal; RD, rhabdomyosarcoma; VACV, vaccinia virus; HBV, hepatitis B virus; HSV, herpes simplex virus; HDACs, histone deacetylases; TSA, trichostatin A; N-C, nuclear-cytoplasmic; EAE, experimental autoimmune encephalomyelitis; IN, integrase; Ub, ubiquitination; CT DNA, calf thymus sonicated DNA; HTLV-1, human T-lymphotropic virus type 1; NTD, N-terminal domain; CTD, C-terminal domain; ISD, interferon stimulatory DNA.
} 
nucleic acids: double-stranded (ds) or single-stranded (ss) DNA and RNA is essential to initiate innate immunity. PRR families include the retinoic acid-inducible gene I (RIG-I)-like receptors, toll-like receptors (TLRs), and a diverse member of cytosolic DNA sensors (Bowie and Haga, 2005; Kaisho and Akira, 2006; Yoneyama and Fujita, 2008; Beutler, 2009; Kawai and Akira, 2009; Yoneyama and Fujita, 2009; Barber, 2011; Keating et al., 2011; Thompson et al., 2011; Paludan and Bowie, 2013; Dempsey and Bowie, 2015). Once PAMPs are sensed by PRRs, the recognition subsequently mediates intracellular signaling pathways and activates transcription factors, interferon (IFN) regulatory factors (IRFs) or nuclear factor $\kappa \mathrm{B}(\mathrm{NF}-\kappa \mathrm{B})$, which in turn leads to the increased production of antiviral interferons and proinflammatory cytokines (Lee and Kim, 2007; Mogensen, 2009).

DNA is a potent trigger of innate immune responses in host cells (Sharma and Fitzgerald, 2011). Many studies have emphasized the importance of cytosolic DNA sensing in the innate immune response against invading pathogens. The DNAmediated innate immune response includes diverse signaling pathways leading to the production of IFN- $\alpha$, IFN- $\beta$, interleukin (IL)-1 $\beta$, or IL-18 (Christensen and Paludan, 2016). For instance, the DNA-dependent activator of IFN-regulatory factors (DAI) (Takaoka, 2007) is the first identified DNA sensor to recognize dsDNA and activate the STING-TBK1-IRF3 signaling pathway. After that, gamma-interferon-inducible protein (IFI16) (Unterholzner et al., 2010; Monroe et al., 2014; Thompson et al., 2014) and DEAD-box helicase 41 (DDX41) (Zhang et al., 2011c) were found as cytosolic DNA sensors in diverse cellular processes to recognize DNA. Leucine-rich repeat flightless-interacting protein 1 (LRRFIP1), another discovered cytosolic DNA sensor, binds dsDNA and activates $\beta$-catenin to induce downstream signaling (Yang et al., 2010). DEAH box protein 9 (DHX9) and DHX36 bind with dsDNA in dendritic cells and activate NF- $\kappa \mathrm{B}$ through myeloid differentiation primary response 88 (MyD88) (Kim et al., 2010; Zhang et al., 2011b). More recently, cyclic GMP-AMP Synthase (cGAS) has been identified as a cytosolic DNA sensor (Gao et al., 2013; Sun et al., 2013; Cai et al., 2014; Zhang et al., 2014; Xia et al., 2016). Once cGAS detects dsDNA, it undergoes a conformational change to open the catalytic pocket followed by synthesis of cGAMP from ATP and GTP: a potent activator of the STINGTBK1-IRF3 signaling pathway. In addition to the induction pathway of IFNs, Absent in melanoma 2 (AIM2) has been found to associate with cytosolic DNA and activate inflammasomes by recruiting apoptosis-associated speck-like protein (ASC) and pro-caspase-1, and then produce mature forms of IL-1 $\beta$ and IL-18 (Burckstuummer, 2009; FernandesAlnemri et al., 2009; Hornung, 2009).

The DNA-mediated innate immune response is not restricted to the induction of type I IFNs and proinflammatory cytokines: cytosolic DNA also induces type III IFNs. Type III IFNs are new members of the IFN family (Ank et al., 2006; Ank and Paludan, 2009; Donnelly and Kotenko, 2010; Kotenko, 2011; Syedbasha and Egli, 2017). Type III IFNs are also called IFN- $\lambda$ s, which include IFN- $\lambda 1$, IFN- $\lambda 2$, IFN- $\lambda 3$ (also known as IL-29, IL-28A, and IL-28B, respectively) and IFN- $\lambda 4$ (Ank et al., 2006; Uzé and Monneron, 2007; Ank and Paludan, 2009; Kotenko, 2011; Booth and George, 2013; Lu et al., 2015). Compared with type I IFNs, they use a different heterodimeric receptor complex (IFN- $\lambda \mathrm{R} 1 /$ IL-10R2) to get into the cells (Ank and Paludan, 2009; Kotenko, 2011). Similar to type I IFNs, stimulation by virus infection or TLR agonist induces type III IFNs (Kotenko et al., 2003; Coccia et al., 2004; Spann et al., 2004). Of note, Donnelly et al. found that the gene encoding the mouse ortholog of human IFNL1 contains a stop codon in the region of exon 1 and lacks the entire exon 2. Therefore, the gene Ifnll in mice does not encode a functional IFN- $\lambda 1$ protein (Donnelly and Kotenko, 2010).

$\mathrm{Ku} 70$ and $\mathrm{Ku} 80$, proteins with molecular weight (MW) of 70 $\mathrm{KDa}$ and $80 \mathrm{KDa}$, respectively, are the essential components in the non-homologous end-joining (NHEJ) pathway. They are first identified in humans (Mimori et al., 1981). Ku70 is encoded by the X-ray repair cross-complementing protein (XRCC) 6 gene located on chromosome 22, and Ku80 is encoded by the XRCC5 gene on chromosome 2. Hetero dimerization of Ku70 and Ku80 is essential for the stability of each protein. The lacking of one subunit leads to dramatically decreased intracellular level of the other subunit, suggesting that most Ku70 and Ku80 exist as a heterodimer (Nussenzweig et al., 1996; Gu et al., 1997). Such functional homologs have been identified in some prokaryotic lineages and almost all eukaryotes, including vertebrates, insects, and fungi (Dynan and Yoo, 1998; Aravind and Koonin, 2001; Bowater and Doherty, 2006). The Ku70/Ku80 heterodimer (socalled $\mathrm{Ku}$ ) and a catalytic kinase subunit (DNA-PKcs) are often referred to as the subunit of the DNA-dependent protein kinase (DNA-PK) complex, which assembles in response to DNA double-strand breaks to repair the damaged DNA via NHEJ pathway (Fell and Schild-Poulter, 2015). The region between residues 439-592 at Ku80 C-terminus interacts with DNA-PKcs (Gell and Jackson, 1999; Singleton et al., 1999; Davis et al., 2013) and promotes the autophosphorylation of DNA-PKcs at DNA double-stranded breaks.

$\mathrm{Ku} 70$ and Ku80 are predominantly observed in the nucleus (Koike, 2002). Following translation of each protein in the cytosol, the $\mathrm{Ku}$ subunits can translocate from the cytoplasm into the nucleus together (Koike, 2002), or independently (Koike et al., 1999a), since each subunit possesses its own nuclear localization signal (NLS) (Koike et al., 2000). However, further functional studies have reported that $\mathrm{Ku} 70$ is not only involved in nuclear activities like DNA repair, transcription, and replication but is also involved in multiple cytosolic activities. Bax, a cytoplasmic protein, has been discovered to interact with $\mathrm{Ku} 70$, and this Ku70-Bax binding is indicated to inhibit Baxmediated apoptosis (Cohen et al., 2004). In addition, many studies have implicated that cytosolic $\mathrm{Ku}$ has been shown to serve as a PRR that recognizes viral DNA in human cells and then induces type I and type III interferons or proinflammatory cytokines (Zhang et al., 2011a; Ferguson et al., 2012; Li et al., 2016b; Sui et al., 2017; Wang et al., 2017; Burleigh et al., 2020; Sui et al., 2021; Wang et al., 2021). This article summarized and discussed the Ku70-mediated innate immune response in detail and then highlighted potential strategies to modulate the 
innate immune cascades. The homology modeling for $\mathrm{Ku} 70$ and $\mathrm{Ku} 80$ is illustrated in Figure 1, the diverse functions of Ku70 are listed in Figure 2. The studies for Ku70 related to innate immunity are summarized in Table $\mathbf{1}$ and illustrated in Figure 3. Beyond the role of Ku70 in innate immunity, roles of Ku70 in viral life cycle of Human Immune deficiency virus (HIV) (Figure 4) and in bacterial pathogen invasion are reviewed and discussed.

\section{STRUCTURE AND DIVERSE FUNCTIONS OF KU70 AND KU80}

Ku70 forms a heterodimer with Ku80. Homology modeling for human $\mathrm{Ku} 70$ and $\mathrm{Ku} 80$, the proteins alone, and the complex with an oligo DNA substrate are shown in Figure 1. The entire structure of $\mathrm{Ku} 70 / \mathrm{Ku} 80$ was not crystallized (Walker et al., 2001) due to the difficult experimental conditions of solving

A

Human Ku70

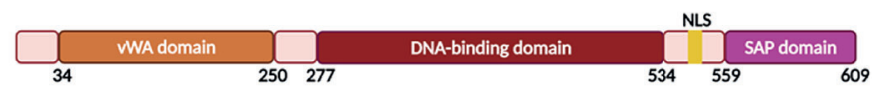

Human Ku80

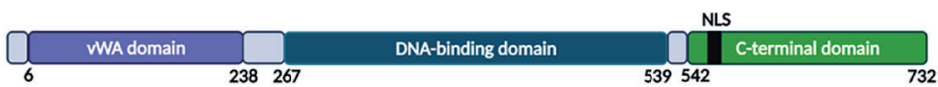

B

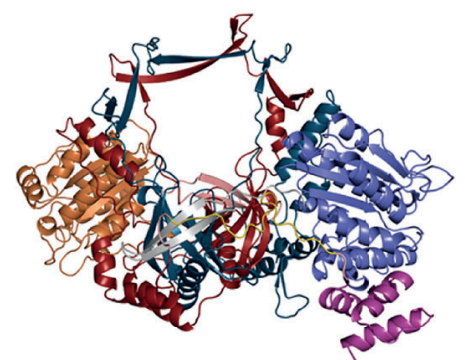

Unbound Ku70/Ku80

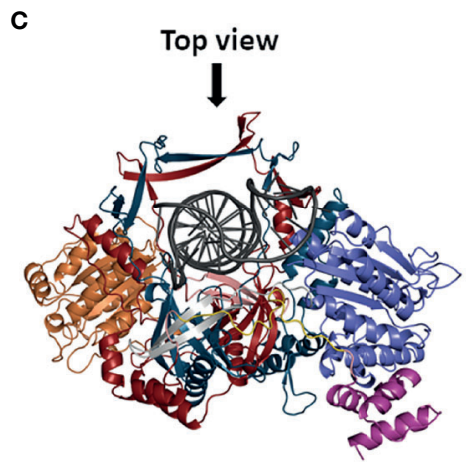

Bound DNA Ku70/Ku80 (side view)

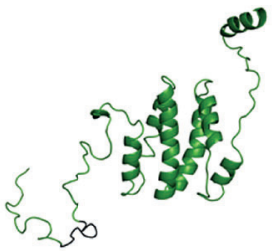

CTD of $\mathrm{Ku} 80$

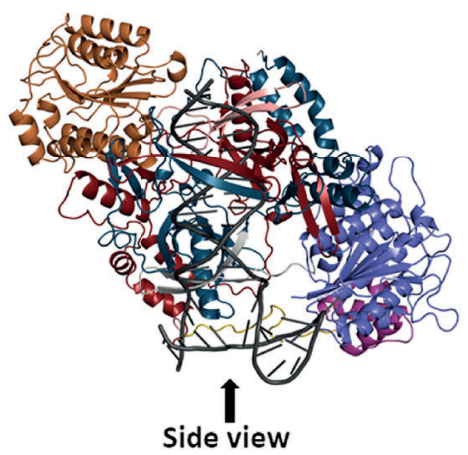

Bound DNA Ku70/Ku80 (top view)

FIGURE 1 | Schematic of Ku70/80 heterodimer domains and ribbon diagrams. (A) Domains in Ku70 and Ku80. In Ku70, the vWA domain is colored in orange, the DNA-binding domain is colored in firebrick, the SAP domain is colored in pink, the nuclear localization sequence (NLS: 539-556) is colored in yellow, and other parts are colored in light pink. In Ku80, the vWA domain is colored in purple, the DNA-binding domain is colored in blue, the c-terminal domain of Ku80 is colored in green, the NLS (561-569) of Ku80 is colored in black, and other parts are colored in light grey. (B) Unbound Ku70/Ku80 heterodimer with a view of Ku70 NLS (yellow) in the front (left panel). The range in the Ku70 model is from 35-609 amino acids, where the first 34 residues in the N-terminal domain (NTD) are truncated. The range in the Ku80 model is from 6-541 amino acids, where the first 5 residues in the NTD and residues 542-732 in the C-terminal domain (CTD) are truncated. The CTD domain of Ku80 is colored in green, and the corresponding NLS (561-569) is colored in black (right panel). (C) The structure model of the Ku70/Ku80 heterodimer bound with DNA. The left and the right panel demonstrate the side and top view, respectively, and bound DNA is colored in dark grey. 


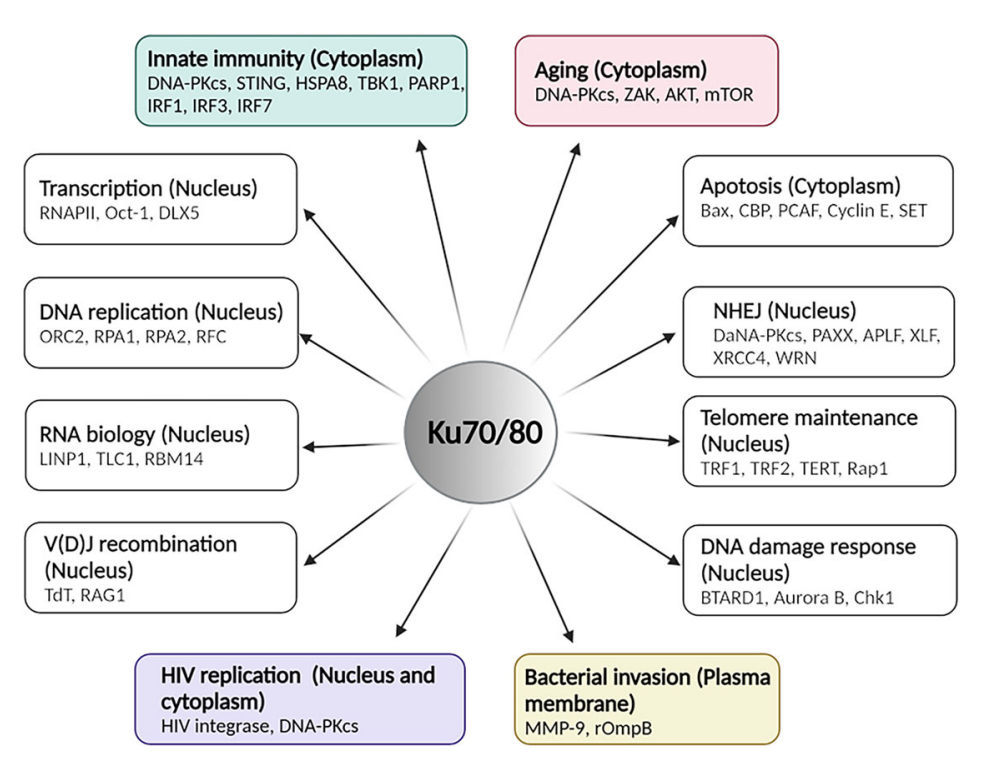

FIGURE 2 | The overview of functions of Ku70/80 heterodimer in various cellular contexts. Ku70/80's involvement in multiple cellular activities with indicated cellular localization and critical mediators. This illustration was created by using BioRender. The figure was adapted from the 2021 review by Abbasi et al. (Abbasi et al., 2021).

regions such as the Ku70 NLS. The homology modeling technique was used here to predict such missing segments. The hetero-oligomeric modeling pipeline implemented in SWISSMODEL (Biasini et al., 2014) was used to predict the Ku70/Ku80 dimer structure. The target sequences of Ku70 (XRCC6, UniProt: P12956) and Ku80 (XRCC5, UniProt: P13010) were used as the input, and the crystal structure (PDB ID: 1JEQ (Walker et al., 2001)) was retrieved as the template for the final modeling. The target modeling segments show high sequence identities with their respective templates when aligned with those templates (95\% for Ku70 and $97 \%$ for Ku80). Finally, the Ku70 structure was modeled, including 575 amino acids with the first 34 amino acids truncated, while the Ku80 structure with amino acids 6541 was modeled. To create the C-terminal domain of the Ku80 model, we used the PDB ID of 6ZHE (Chaplin et al., 2021) as the template due to its relative completeness in this domain (Figure 1B). For incorporating the DNA coordinate into the Ku70/Ku80 model (Figure 1C), the PDB structure of 1JEY (Walker et al., 2001) was used as the anchor for fitting the model. Both the Ku70 and Ku80 protein possess a three-domain topology, including an N-terminal vWA (von Willebrand factor A) domain, a DNA-binding domain, and a C-terminal arm (Walker et al., 2001) (Figure 1A). The homology modeling of $\mathrm{Ku}$ heterodimer suggested a quasi-symmetric basket-like molecule with a narrow-preformed ring, which facilitates the binding of DNA to $\mathrm{Ku}$ (Walker et al., 2001) (Figures 1B, C).

The N-terminal vWA domains of Ku70 or Ku80 are composed of a six-stranded $\beta$-sheet in a Rossman fold (Walker et al., 2001). Disrupting the vWA domains in yeast Ku70/80 has been found to impair the function of $\mathrm{Ku}$ in DNA repair and telomere regulation (Ribes-Zamora et al., 2007). Although the amino edge of the vWA domain locates close to the DNA-binding groove, the vWA domain is not required for DNA binding. However, the Ku vWA domains may facilitate protein-protein interactions. For instance, the vWA domain of Ku80 has been found to interact with APLF, an NHEJ repair protein important for recruiting other repair factors (Grundy et al., 2013). So, the N-terminal vWA domains have minimal contribution to heterodimerization or DNA binding but are potentially involved in protein-protein interactions.

Meanwhile, the middle domain consists of a seven-stranded anti-parallel $\beta$-barrel and plays an essential role in $\mathrm{Ku}$ DNA binding and heterodimerization (Walker et al., 2001). Heterodimerization leads to a positively charged DNA-binding ring that fits sterically around the minor and major DNA grooves. Ku threads inwards on DNA like a nut threaded onto a bolt, with Ku70 positioned close and Ku80 far away to the DNA end (Yoo et al., 1999; Doherty and Jackson, 2001; Abbasi et al., 2021). Ku binds to dsDNA ends, $5^{\prime}$ and $3^{\prime}$ overhangs, or blunt ends with a higher binding affinity $\left(\mathrm{Kd}=10^{-9} \mathrm{M}\right)$. And it has a much lower binding affinity with circular DNA or the ends of single-stranded DNA (ss DNA) (Fell and Schild-Poulter, 2015).

$\mathrm{C}$ terminal regions of $\mathrm{Ku}$ contain a flexible linker and a globular structural domain (Figure 1). The C-terminal region of Ku70 contains a SAP (SAF-A/B, Acinus, and PIAS) domain encoded by residues 559-609 (Walker et al., 2001). Studies on other SAP domain proteins have implicated that SAP domains can bind DNA (Göhring et al., 1997; Suzuki et al., 2009). Using a pair of even shorter versions of Ku70, the Ku70_251-438 and Ku70_439-609 truncated mutants, Anisenko et al. have determined that the dsDNA is bound within the C-terminal part of the protein containing SAP domain (Anisenko et al., 2017b). While DNA binding to $\mathrm{Ku}$, the SAP domain undergoes 
displacement, making itself close to the DNA-binding region of the Ku heterodimer (Rivera-Calzada et al., 2007; Makowski et al., 2016). Even the exact function of Ku70-SAP has not been completely investigated yet, the helical C-terminal arms of $\mathrm{Ku}$ contribute to heterodimerization and stabilize the interaction of Ku to DNA (Walker et al., 2001; Keijzers, 2018).

Notably, Ku70 and Ku80 per se possess an NLS in the molecule (as shown in Figure 1 with Ku70 NLS in yellow and Ku80 NLS in black). The various NLS are classified into two types based on the pattern of molecular sequences: (1) a single cluster of basic amino acids, such as the NLS of the SV40 Tantigen, and (2) a bipartite type in which two basic amino acid regions are separated by a stretch of approximately 10 non-basic amino acids (Görlich and Mattaj, 1996). The Ku70 NLS belongs to type 2, and the sequence of Ku70 NLS is highly conserved among human, mouse, rat, hamster, and chicken (Koike et al., 1999b). While importing into the nucleus of the cells, the Ku70 NLS is recognized by the nuclear targeting complex, PTAC58, and PTAC97 (Koike et al., 1999b). Given that Ku70 is an NLSpossessing protein, it has been found predominately in the nucleus of unstimulated cells, such as HeLa, HEK (human embryonic kidney cells), and rhabdomyosarcoma (RD) cells (Sui et al., 2021).

Consistent with the illustrated structure, many studies have suggested that $\mathrm{Ku}$ possesses unusual DNA-binding properties, binding potently to the ends of dsDNA molecules in a sequenceindependent manner. The unusual end-binding properties are required for various nuclear processes, such as NHEJ DNA repair (Critchlow and Jackson, 1998; Dobbs et al., 2010; Radhakrishnan et al., 2014; Menon and Povirk, 2016; Scully et al., 2019), V(D)J recombination of immunoglobin (Jackson and Jeggo, 1995; Fugmann et al., 2000; Bassing et al., 2002), telomerase maintenance (Bertuch and Lundblad, 2003; Indiviglio and Bertuch, 2009; Wood et al., 2015; Shay and Wright, 2019; Sui et al., 2020), transcription (Li et al., 1995; Giffin et al., 1996; Ono et al., 1996; Giffin et al., 1997; Dynan and Yoo, 1998; Mo and Dynan, 2002; Bunch et al., 2015), DNA damage response (Wang et al., 2000; Zhou and Elledge, 2000; Rouse and Jackson, 2002; Harper and Elledge, 2007; Jackson and Bartek, 2009; Fell and Schild-Poulter, 2012; Nowsheen and Yang, 2012; Blackford and Jackson, 2017), RNA biology (Yoo and Dynan, 1998; Peterson et al., 2001; Stellwagen et al., 2003; Ting et al., 2005; Pfingsten et al., 2012; Lamaa et al., 2016; Zhang et al., 2016b; Dutertre and Vagner, 2017; Shao et al., 2020; Thapar et al., 2020), and DNA replication (Barnes and Rio, 1997; Shao et al., 1999; Novac et al., 2001; Cosgrove et al., 2002; Matheos et al., 2002; Schild-Poulter et al., 2003; Park et al., 2004; Rampakakis et al., 2008; Miyoshi et al., 2009; Foster et al., 2011; Abdelbaqi et al., 2013; Sánchez and Russell, 2015; Teixeira-Silva et al., 2017). Such unusual DNAbinding properties also facilitate Ku70's activities in the cytoplasm of the cells. Those activities include participating in Bax-mediated apoptosis (Cohen et al., 2004; Gomez et al., 2007; Mazumder et al., 2007; Kim et al., 2014) and serving as a cytosolic DNA sensor to activate the DNA-mediated innate immune response. An overview of Ku70/80 heterodimer functions in the various cellular processes is illustrated in
Figure 2. In the following paragraphs, we will discuss roles of Ku70 in innate immunity, aging-related cytoplasmic DNA sensing, HIV replication and bacterial invasion in detail.

\section{KU70 IS IDENTIFIED AS A NOVEL CYTOSOLIC DNA SENSOR THAT MEDIATES INNATE IMMUNE RESPONSES}

Our lab previously reported, for the first time, that $\mathrm{Ku} 70$ is a novel DNA sensor to induce expression of IFN- $\lambda 1$ rather than that of type-I IFNs (Zhang et al., 2011a). Plasmid DNA transfection or DNA virus infection-mediated IFN- $\lambda 1$ induction was detected in HEK cells, RD cells, monocytederived macrophages, immature dendric cells, and-with a much lesser level-HeLa cells (Zhang et al., 2011a). These results indicated that the Ku70-mediated IFN- $\lambda 1$ induction is consistently presented in multiple cell types.

Different forms of DNA transfection (e.g., single-stranded DNA, fragmented human genomic DNA, and bacterial DNA) and infection of DNA virus induce IFN- $\lambda 1$ (Zhang et al., 2011a); IFN- $\lambda 1$ mRNA was induced by both supercoiled or linearized forms of DNA plasmids. However, the linearized plasmid DNA significantly enhanced activation. This result was consistently supported by the property of $\mathrm{Ku}$, which detects the end structure of DNA. Zhang et al. confirmed that over $500 \mathrm{bp}$ of DNA triggers IFN- $\lambda 1$ induction with the dependency of DNA length. By contrast, the production of IFN- $\lambda 1$ was not detected with the transfection of DNA that was only $50 \mathrm{bp}$ in length (Zhang et al., 2011a). One study demonstrated that titration of $\mathrm{Ku}$ to a fixed amount of linear dsDNA fragments produced ladders of shifted bands, which are proportional to the length of DNA. This data implicated that many Ku heterodimers bind to multiple sites on one dsDNA in a sequence-independent pattern (Blier et al., 1993). Based on those $\mathrm{Ku}$ properties, it was apparent that $\mathrm{Ku} 70$ induces activation of IFN- $\lambda 1$ and that Ku70 recognizes intracellular DNA by DNA transfection or infection with a DNA virus, such as herpes simplex virus (HSV) type 1 (HSV-1) or type 2 (HSV-2), without any restriction in structure or sequence (Zhang et al., 2011a).

In addition to the fact that Ku70 senses DNA to induce type III IFNs, subsequent other studies indicated that Ku70 perse, or Ku70 in $\mathrm{Ku} 70 / \mathrm{Ku} 80$ heterodimer, or Ku70 in the DNA-PK complex involves in the induction of type I IFNs and other inflammatory cytokines directly or indirectly. For example, Ku70 has also been reported to detect human T-lymphotropic virus type 1 (HTLV-1) reverse intermediate product ssDNA90 and induce IFN- $\alpha$, IFN- $\beta$, IFN- $\lambda$, and RANTES (Wang et al., 2017). Additionally, the Ku70/ Ku80 heterodimer senses the in vitro adenovirus-delivered hepatitis B virus (HBV) DNA and induces CCL3 and CCL5, thereby implicating that Ku70 modulates HBV replication (Li et al., 2016b). More interestingly, a recent study suggested that the Ku70/80 complex senses cytoplasmic DNA in aged $\mathrm{CD} 4^{+} \mathrm{T}$ cells and that this detection potentiated T-cell activation and agingrelated autoimmune responses (Wang et al., 2021). Furthermore, 
TABLE 1 | List of studies about Ku70-involved innate immune response.

\begin{tabular}{|c|c|c|c|c|c|c|}
\hline $\begin{array}{l}\text { Sensor } \\
\text { proteins }\end{array}$ & $\begin{array}{l}\text { The source of } \\
\text { nucleotides }\end{array}$ & Host cells & Signaling pathway & $\begin{array}{l}\text { Induced } \\
\text { cytokines }\end{array}$ & In vivo & References \\
\hline Ku70 & $\begin{array}{l}\text { Plasmid DNA, bacterial } \\
\text { DNA. HSV-2G, HSV-1 }\end{array}$ & HEK, RD, THP-1, macrophages & $\begin{array}{l}\text { STING-TBK1-IRF3, IRF1, and } \\
\text { IRF7 pathway }\end{array}$ & IFN- $\lambda 1$ & $\mathrm{~N} / \mathrm{A}$ & $\begin{array}{l}\text { (Zhang et al., } \\
\text { 2011a; } \\
\text { Sui et al., } \\
\text { 2017; } \\
\text { Sui et al., } \\
\text { 2021) }\end{array}$ \\
\hline DNA-PK & $\begin{array}{l}\text { VACV, E. coli, ISD, HSV-1, } \\
\text { MVA }\end{array}$ & Fibroblasts, MEF & STING-TBK1-IRF3 & $\begin{array}{l}\text { IFN- } \beta, \text { CXCL10, } \\
\text { IL-6 }\end{array}$ & Mice & $\begin{array}{l}\text { (Ferguson } \\
\text { et al., 2012; } \\
\text { Peters et al., } \\
\text { 2013; } \\
\text { Scutts et al., } \\
\text { 2018) }\end{array}$ \\
\hline Ku70 & pAAV-HBV plasmid, HBV & $\begin{array}{l}\text { Liver-derived cells: Sk-Hep-1, Hep } \\
\text { G2, Huh7, primary HSECs }\end{array}$ & DNA-PKcs and PARP1-IRF1 & CCL3, CCL5 & $\begin{array}{l}\text { HBV-infected } \\
\text { human patients }\end{array}$ & $\begin{array}{l}\text { (Li et al., } \\
\text { 2016b) }\end{array}$ \\
\hline Ku70 & HTLV-1 RTI ssDNA90 & HeLa cells, PMA-THP-1 & STING-TBK1-IRF3 & $\begin{array}{l}\text { IFN- } \beta \text {, IFN- } \lambda \text {, and } \\
\text { TNF- } \alpha\end{array}$ & N/A & $\begin{array}{l}\text { (Wang et al., } \\
\text { 2017) }\end{array}$ \\
\hline DNA-PK & CT DNA & $\begin{array}{l}\text { Human U937 cells, } \\
\text { primary human hepatocytes, human } \\
\text { fibroblasts }\end{array}$ & $\begin{array}{l}\text { HSPA8-IRF3 (STING- } \\
\text { independent sensing pathway) }\end{array}$ & $\mathrm{IFN}-\beta$ & $\mathrm{N} / \mathrm{A}$ & $\begin{array}{l}\text { (Burleigh } \\
\text { et al., 2020) }\end{array}$ \\
\hline $\begin{array}{l}\text { Ku70/ } \\
\text { Ku80 }\end{array}$ & ISD & Jurkat T cells, aged CD4+ T cells & ZAK-AKT-mTOR & $\begin{array}{l}\text { IL-2, IFN- } \gamma, \mathrm{T} \text {-cell } \\
\text { proliferation }\end{array}$ & Mice & $\begin{array}{l}\text { (Wang et al., } \\
\text { 2021) }\end{array}$ \\
\hline
\end{tabular}

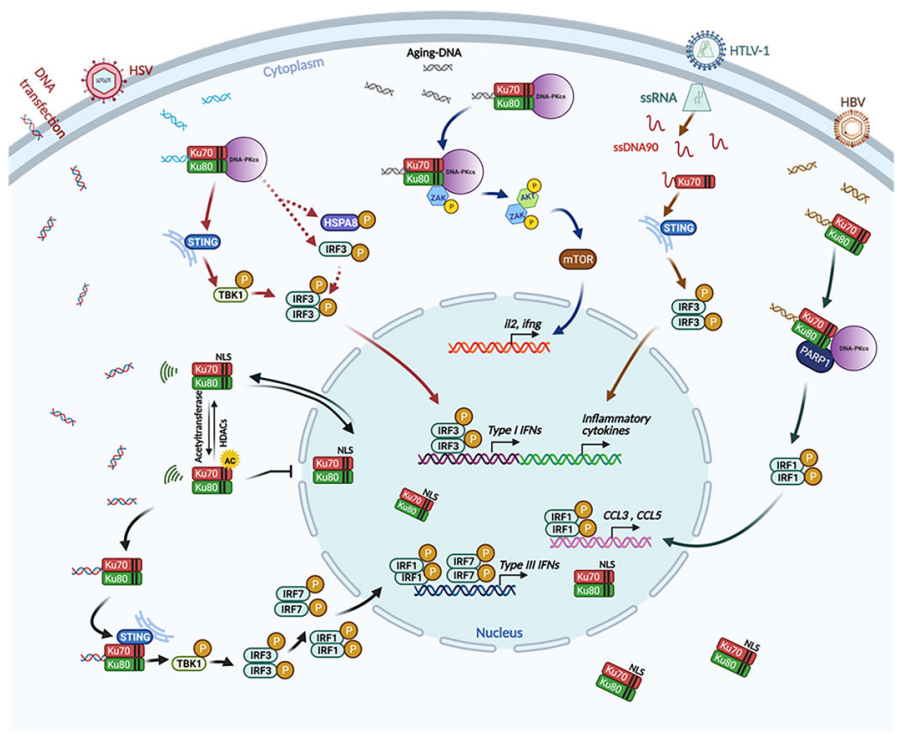

FIGURE 3 | The involvement of Ku70 as a cytosolic DNA sensor to activate the innate immune response. Ku70 is identified as a cytosolic DNA sensor that induces type III IFNs through a STING-TBK1-IRF3, IRF1, and IRF7 signaling pathway. In this signaling pathway, cytoplasmic translocation of Ku70 is an initial and essential step (black arrows) (Zhang et al., 2011a; Sui et al., 2017; Sui et al., 2021); Ku70 and Ku80, together with DNA-PKcs (DNA-PK), are also involved in a STINGdependent (Ferguson et al., 2012) (solid arrow) and STING-independent (Burleigh et al., 2020) (dashed arrow) pathway to induce type I IFNs (red arrows). Ku70 is reported to sense HTLV-1 transcription intermediate product ssDNA90 and interacts with STING to induce IFNs and inflammatory cytokines, thereby modulating HTLV-1 replication (Wang et al., 2017) (brown arrows). The Ku70/80 heterodimer recognizes HBV-infection-derived DNA, then activates DNA-PKcs and PARP1 to induce CCL3 and CCL5 inflammatory cytokines (Li et al., 2016b) (green arrows). DNA-PK (the complex of DNA-PKcs, Ku70, and Ku80) senses aging-related cytoplasmic DNA in CD4+ T cells. This DNA sensing then induces T-cell proliferation and activation, as well as autoimmunity through the ZAK-AKT-mTOR pathway (Wang et al., 2021) (blue arrows). This illustration was created by using BioRender.

Ferguson et al. reported that DNA-PK, a heterotrimeric protein complex composed of $\mathrm{Ku} 70, \mathrm{Ku} 80$, and DNA-PKcs, is able to activate downstream STING-TBK1-IRF3 signaling pathway when it recognizes foreign DNA (Ferguson et al., 2012). It has been further demonstrated that DNA-PK co-localizes with vaccinia virus (VACV) DNA during VACV infection. Virus infectionmediated IFN response is aborted when the components of DNAPK were knocked-out (Ferguson et al., 2012). 
$\mathrm{Ku} 70, \mathrm{Ku}$ protein, or DNA-PK have been implicated in having a role in sensing a variety of DNA or DNA viruses without restrictions. More importantly, many other DNA sensors, such as cGAS, require binding of double-stranded DNA to activate the sensor protein: a conformation change, thereby activating downstream signaling (Cai et al., 2014; Dempsey and Bowie, 2015; Xia et al., 2016). However, the Ku protein or DNA-PK complex does not have such conformational restriction; therefore, the $\mathrm{Ku} / \mathrm{DNA}-\mathrm{PK}$-mediated innate immune response may become a perfect complementary pathway in the host defense system when other DNA-sensing pathways are impaired.

\section{THE DOWNSTREAM SIGNALING PATHWAY OF KU70}

Many studies have indicated that $\mathrm{Ku} 70$, as a cytosolic DNA sensor, binds with DNA and mediates the downstream signaling pathway. However, "What is the adapter at the downstream signaling of Ku70?" was the next question. In $\mathrm{Ku} 70$-mediated type III IFN response, an investigation was initiated from the observation of IFN- $\lambda 1$ induction in HEK and 293 T (SV40-T antigen transformed HEK cell line) cells with GFPencoding DNA plasmid transfection. With a similar green fluorescence signal observed between HEK 293 cells and 293T cells, DNA-induced IFN- $\lambda 1$ induction was detected in HEK 293 cells but not in $293 \mathrm{~T}$ cells. By comparing the expression level among different signal mediators associated with the cytosolic sensor, we found that the stimulator of interferon genes (STING) is not endogenously expressed in $293 \mathrm{~T}$ cells. The gain-of-function and loss-of-function study confirmed the hypothesis that STING is the downstream adaptor of $\mathrm{Ku} 70$ to activate the IFN- $\lambda 1$ signaling pathway. The co-immunoprecipitation assay further illustrated that Ku70 interacts with STING in the cytoplasm and forms a complex upon DNA stimulation (Sui et al., 2017). At this point, the activating pathway is quite similar to the DNAPK-mediated STING-dependent pathway. DNA-PK was reported as a DNA cytosolic sensor to induce IFN- $\alpha$ or IFN- $\beta$ (Ferguson et al., 2012). However, the interaction between DNA-PK and the downstream STING is in a transient pattern. After binding at three hours after DNA stimulation, STING dissociates from the complex, and this dissociation activates downstream signaling (Ferguson et al., 2012). STING is also the downstream target of $\mathrm{Ku} 70$ in sensing HTLV-1 intermediate product ssDNA90 and, therefore, induces type I interferons and inflammatory cytokines through phosphorylation of IRF3 (Wang et al., 2017).

In addition to STING as the downstream adaptor of $\mathrm{Ku} 70$ or DNA-PK, other proteins, namely DNA-PKcs and PARP1, are also reported as the adaptor proteins to $\mathrm{Ku} 70 / 80$ in sensing $\mathrm{HBV}$ DNA (Li et al., 2016b). While sensing aging-related DNA cytoplasmic accumulation, DNA-PK interacts with ZAK, AKT, and $\mathrm{mTOR}$, inducing $\mathrm{T}$-cell proliferation and aging-related autoimmunity (Wang et al., 2021). Another study recently claimed that DNA-PK is a potent sensor that activates the innate immune response with STING-independent signaling pathway. However, this pathway only exists in human cells and is not present in mouse cells (Burleigh et al., 2020). In this pathway, HSPA8/HSC70 is the adaptor protein for inducible phosphorylation and then activates downstream innate immune signaling (Burleigh et al., 2020). All those different Ku70-involved mechanisms determine the diverse patterns of innate immune response in a cell-type-dependent pattern. The coexistence of various molecular mechanisms is always an interesting topic in the research field of innate immunity.

Compared with the induction of type I IFNs, the kinetics of Ku70-mediated IFN- $\lambda 1$ induction indicates a delayed induction profile. The IFN- $\lambda 1$ mRNA expression is initiated at about 12 hours after DNA transfection. A profound protein level of IFN- $\lambda 1$ can be detected at 48 hours after DNA transfection (Sui et al., 2017). As we know, cGAS- or IFI16-mediated innate immune response is usually induced as an earlier event after stimulation: for example, at six hours after stimulation (Unterholzner et al., 2010; Sun et al., 2013; Cai et al., 2014). The activation of downstream of cGAS or IFI16 is the STING-TBK1-IRF3 signaling pathway. IRF3 is endogenously expressed in most cells. The activation of IRF3 is detected at three hours after stimulation, indicating that IRF3 facilitates the induction as a faster and earlier event. By contrast, Ku70-mediated IFN- $\lambda 1$ induction relies on activating the STING-TBK1-IRF3, IRF1, and IRF7 axis (Zhang et al., 2011a; Sui et al., 2017). IRF3 is activated first to produce a profound expression of IRF1 and IRF7, since IRF1 and IRF7 are not endogenously expressed in the cells. Once IRF 1 and IRF7 are produced, IFN- $\lambda 1$ and then can be significantly induced. In summary, similar to other DNA sensor-mediated innate immune responses, the kinetics of Ku70 involved innate immune response depends on the specific signaling pathway by which interferon or inflammatory cytokines are produced.

\section{THE CYTOPLASMIC TRANSLOCATION OF KU70 IS THE INITIAL STEP FOR KU70 AS A CYTOSOLIC DNA SENSOR}

Ku70 was initially characterized as a DNA repair protein; its primary function serves in the nucleus. However, more and more studies have identified Ku70 as a cytosolic DNA sensor that mediates innate immune response. The downstream adaptor STING and another protein, HSPA8, were all found in the cells' cytoplasm (Ferguson et al., 2012; Sui et al., 2017; Burleigh et al., 2020). So how can a nuclear protein sense cytosolic DNA and thereby initiate a downstream signaling pathway? This question led to identify the molecular mechanism at an earlier time point. In the case of Ku70-mediated IFN- $\lambda 1$ induction by DNA transfection, Ku70 was observed predominately located in the cytoplasm of the cells, thereby facilitating the interaction between STING and Ku70 (Sui et al., 2017). So, it was speculated that upon DNA stimulation, Ku70 translocates from the nucleus to the cytoplasm of the cells. And this process is closely correlated with the induction of IFN- $\lambda 1$.

The subsequent study using confocal microscopy confirmed that the cytoplasmic translocation of Ku70 is observed in the cells 
in which IFN- $\lambda 1$ is induced by DNA transfection, such as HEK and RD cells. And consistently, such cytoplasmic translocation of $\mathrm{Ku} 70$ is not observed in HeLa cells, and similarly, DNA transfection does not induce IFN- $\lambda 1$ induction in HeLa cells (Sui et al., 2021). In addition to DNA plasmid transfection, HSV1 , a DNA virus infection, also triggered the cytoplasmic translocation in HEK cells with a virus-strain-dependent manner. Ku70 cytoplasmic translocation and IFN- $\lambda 1$ induction only in HEK cells infected with the HSV-1 McKrae strain. Those results further emphasized that the cytoplasmic translocation of $\mathrm{Ku} 70$ is a required step for $\mathrm{Ku} 70$-mediated IFN- $\lambda 1$ induction (Sui et al., 2021). A quantification analysis with Western blot using cytosolic fractions was adapted to characterize the accumulation kinetics of cytoplasmic Ku70. The data demonstrated that the cytoplasmic translocation of Ku70 was started right after DNA stimulation and obtained the highest level at six hours after transfection, and then the accumulation of cytoplasmic Ku70 returned to a similar level as that in unstimulated cells (Sui et al., 2021). These data testified two points. First, the cytoplasmic translocation of $\mathrm{Ku} 70$ is a kinetics process. Ku70 translocates freely from the nucleus to the cytoplasm or from the cytoplasm back to the nucleus. How DNA transfection triggers the translocation remains unclear, but we hypothesized it is due to a change in a dynamic balance between the accumulation level of Ku70 in the nuclear and the cytoplasm. When cytosolic Ku70 recognizes and associates with cytoplasmic DNA, such interaction may interrupt the equilibrium between the cytosolic and the nuclear Ku70 and then drive the translocation of Ku70 from the nucleus to the cytoplasm. Second, the kinetic study further demonstrated that the translocation of $\mathrm{Ku} 70$ from the nucleus to the cytoplasm is an initial and essential step in the DNA-mediated IFN- $\lambda 1$ innate immune response. Compared with the time course of IFN- $\lambda 1$ induction, the translocation of Ku70 occurred one hour right after DNA transfection and peaked at six hours. All this happened before IFN- $\lambda 1$ induction. Consequently, it is reasonable to speculate that the translocation of $\mathrm{Ku} 70$ happened first and that IFN- $\lambda 1$ induction occurred later since we further confirmed that recombinant IFN- $\lambda 1$ does not induce the cytoplasmic translocation of Ku70 (Sui et al., 2021). Like $\mathrm{Ku} 70$, IFI16, another DNA sensor protein, has been reported to recognize and sense DNA not only in the cytoplasm but also in the nucleus of the cells, and its sensing capabilities depend on the distribution of IFI16 (Li et al., 2012; Dell'oste et al., 2014; Ansari et al., 2015). IFI16 detects and binds to herpes viral DNA in the nucleus of the cells. However, detection of transfected DNA or cytoplasmic viral DNA occurs in the cytoplasm. Ku70 ubiquitously expresses in the nucleus as a nuclear protein; however, there is no evidence to indicate that $\mathrm{Ku} 70$ can also serve as a nuclear DNA sensor protein.

In addition to our detailed study about the cytoplasmic translocation of $\mathrm{Ku} 70$, $\mathrm{Li}$ et al. also reported that the cytoplasmic-translocated Ku70/Ku80 complex senses HBV DNA and then induces hepatitis-associated chemokine secretion (Li et al., 2016b). This kind of nuclear-cytoplasmic (N-C) trafficking has become a conventional mechanism for these multifunctional DNA sensors. As we know, cGAS recognizes cytosolic DNA. This detection produces the second messenger 2'3'-cGAMP, and the cGAMP in turn initiates STING-dependent downstream signaling to induce type I IFNs. However, more recently, Sun et al. demonstrated that cGAS is located both in the cytoplasm and in the nucleus, and cGAS is required to export into the cytoplasm in response to DNA stimulation. (Sun et al., 2021). Therefore, the N-C trafficking is required for $\mathrm{Ku} 70$ and other multiple-functional proteins to conduct their cytosolic and nuclear activities.

\section{THE COOPERATIVE PATTERN OF KU70, KU80, AND DNA-PKcs IN MEDIATING INNATE IMMUNE RESPONSE}

$\mathrm{Ku} 70$ is a subunit of the heterotrimeric protein complex DNAPK composing of Ku80 and the catalytic subunit DNA-PKcs. While we identified Ku70 as a novel cytosolic DNA sensor that induces IFN- $\lambda 1$ innate immune response (Zhang et al., 2011a; Sui et al., 2017; Sui et al., 2021), we hope to determine whether Ku80 or DNA-PKcs are also involved in the cytosolic-DNAsensing activity.

It has been reported that DNA-PK serves as a PRR, recognizing cytoplasmic DNA and inducing the production of type I IFNs (Ferguson et al., 2012; Burleigh et al., 2020). The Ku heterodimer (Walker et al., 2001) and DNA-PKcs (Hammarsten and Chu, 1998) can directly bind to DNA; however, in the absence of either Ku70 or Ku80, the binding affinity of DNAPKcs with DNA is dramatically decreased (Yaneva et al., 1997). These findings implicated that each subunit of the DNA-PK complex plays an essential role. Consistent with this study, we also observed the existence of Ku80, but not DNA-PKcs, in the complex of Ku70-STING (Sui et al., 2017). Additionally, we observed the co-localization of $\mathrm{Ku} 80$ with $\mathrm{Ku} 70$ in the nucleus of unstimulated cells and the cytoplasm of DNA-transfectionstimulated cells. Those data suggest that Ku80 is translocated with $\mathrm{Ku} 70$ from the nucleus to the cytoplasm (Sui et al., 2021).

However, we previously reported that DNA-mediated IFN- $\lambda 1$ induction substantially decreased, when $\mathrm{Ku} 70$ is transiently knocked down; in contrast, knocking down of Ku80 has no impact on the induction of IFN- $\lambda 1$. To further validate the role of $\mathrm{Ku} 70$ and Ku80 in DNA-mediated innate immune response, the IFN- $\lambda 1$ promoter reporter assay by overexpressing each subunit was utilized in the study. The result from the assay consistently demonstrated that overexpression of Ku70 highly activates the IFN- $\lambda 1$ promoter. However, the overexpression of Ku80 had no impact on IFN- $\lambda 1$ promoter activation. Moreover, the results of the co-immunoprecipitation assay directly exclude the presence of DNA-PKcs in the complex of Ku70-STING. Therefore, all those studies suggested that Ku80 and DNA-PKcs may not be directly involved in DNA-mediated IFN- $\lambda 1$ induction (Zhang et al., 2011a; Sui et al., 2017).

In studies about DNA-PK as the cytosolic DNA sensor to induce the innate immune response, it seems that DNA-PKcs is the key factor to mediate downstream signaling and that the involvement of Ku70 or Ku80 enhances the sensing capability of 
DNA-PKcs (Ferguson et al., 2012; Burleigh et al., 2020). In HBV infection, the Ku70/80 complex senses infected HBV DNA, and DNA-PKcs and PARP1 act as a downstream adaptor to activate hepatitis-associated chemokine secretion (Li et al., 2016b).

$\mathrm{Ku} 70$-involved innate immune response shows various patterns for the participation and function of $\mathrm{Ku} 70, \mathrm{Ku} 80$, and DNA-PKcs. In general, like their function in the DNA repair process, they work together as a whole complex (Ferguson et al., 2012; Burleigh et al., 2020; Wang et al., 2021), but in the case of type-III IFN response and Ku70 sensing HTLV-1, the functional element is $\mathrm{Ku} 70$ itself. However, we have become aware that when $\mathrm{Ku} 70$ or Ku80 is expressed individually, neither of them are stable (Satoh et al., 1995) and that the absence of one of the subunits leads to a remarkable reduction in the stable level of the other one (Errami et al., 1996; Gu et al., 1997; Singleton et al., 1997). Consequently, it is hard to precisely elucidate the function of Ku70 or Ku80 alone by completely knocking out one or the other. Further study will help to illuminate the detailed molecular mechanism of how Ku70, Ku80, or DNA-PKcs cooperate and facilitate DNA-sensing activity.

\section{THE POTENTIAL REGULATION FACTORS INVOLVED IN KU70-MEDIATED INNATE IMMUNE RESPONSE}

Further studies have reported that Ku70, predominantly located in the nucleus of the cells, has a cytoplasmic translocation from the nucleus, then conducts its cytosolic activities, such as sensing invading cytosolic DNA to induce an innate immune response (Zhang et al., 2011a; Sui et al., 2017; Sui et al., 2021) or binding with invading viral elements/proteins to modulate virus replication (Li et al., 2016b). Therefore, abundant amounts of cytoplasmic protein accumulation seem to be essential for Ku70 to successfully recognize cytosolic DNA and activate the downstream IFN signaling pathway. Our observations, nuclear retention of $\mathrm{Ku} 70$, because of the treatment with leptomycin $\mathrm{B}$, severely attenuates the IFN- $\lambda 1$ response to DNA stimulation (Sui et al., 2021), indicating that cytoplasmic translocation is a critical factor for Ku70's cytosolic DNA sensing.

Our group confirmed that acetylation at $\mathrm{Ku} 70-\mathrm{NLS}$ regulates the localization of Ku70 in the nucleus or in the cytoplasm, which is consistent with the finding from other groups (Fujimoto et al., 2018), and we first reported that acetylation modulates Ku70's DNA-sensing activity (Sui et al., 2021). While importing into the nucleus, Ku70 has to interact with the $\operatorname{Imp} \alpha / \operatorname{Imp} \beta$ complex to facilitate nuclear translocation. With the acetylation at the region of Ku70-NLS, the interaction between acetylated Ku70 and the $\operatorname{Imp} \alpha / \operatorname{Imp} \beta$ complex is severely decreased. Therefore, acetylated $\mathrm{Ku} 70$ is predominantly located in the cytoplasm of the cells (Fujimoto et al., 2018). In line with Fujimoto's finding, we further demonstrated that acetylated Ku70 highly induces DNAmediated IFN- $\lambda 1$ induction (Sui et al., 2021).

The acetylation level of a protein depends on the dynamic balance between the activity of acetylation and deacetylation enzymes (Ansari et al., 2015; Gong et al., 2019). Multiple lysine residues have been identified as acetylation locations on $\mathrm{Ku} 70$ and Ku80 (Cohen et al., 2004; Subramanian et al., 2013; AlEmam et al., 2014; Koike et al., 2017). Acetylation at Ku70 lysine residues, K539, K542 (Subramanian et al., 2005; Subramanian et al., 2013) and K317, K331, K338 (Al-Emam et al., 2014) impaired the function of $\mathrm{Ku} 70$ in NHEJ, since those lysine residues of $\mathrm{Ku} 70$ are required for Ku70 binding with dsDNA ends during NHEJ process. Two histone acetyltransferase enzymes, $\mathrm{CBP}$ and PCAF, are responsible for $\mathrm{Ku}$ acetylation (Cohen et al., 2004). Histone deacetylases (HDACs), a family of deacetylation enzymes, regulate the deacetylation of multiple non-histone proteins and, therefore, impact functions by changing their activity, such as cellular localization and protein-protein interactions (Subramanian et al., 2005; Roger et al., 2011). More than 50 non-histone proteins, including p53 and $\mathrm{Ku} 70$, have been defined as the substrates of HDACs (Chaudhary et al., 2014; Gong et al., 2019). Trichostatin A (TSA), an inhibitor sensitive to class I/II deacetylases, was utilized in our study to evaluate the impact of this deacetylase inhibitor on the Ku70 cytoplasmic accumulation and DNAmediated IFN- $\lambda 1$ induction. The data implicated that TSA treatment dose-dependently enhances the cytoplasmic accumulation of Ku70 and increases DNA-mediated IFN- $\lambda 1$ induction. (Sui et al., 2021). As we demonstrated in our study, the relationship of the acetylation levels of Ku70 and DNAmediated innate immune response may provide a simple and elegant strategy, modulating the acetylation levels of the target protein to regulate its localization-dependent activities.

$\mathrm{Ku} 70$ and Ku80 are generally believed to always form heterodimers. And it has been consistently confirmed in our previous study that Ku80 translocates from the nucleus to the cytoplasm together with Ku70. The confocal microscopy analysis indicated that Ku70 and Ku80 colocalized together in the nucleus of unstimulated cells, and then both translocate from the nucleus to the cytoplasm upon a DNA stimulation (Sui et al., 2021). However, Koik et al. demonstrated that the localization of Ku80 does not entirely coincide with that of $\mathrm{Ku} 70, \mathrm{Ku} 80$ protein was transported to the nucleus without heterodimerization with Ku70. The Ku80 NLS was demonstrated to be mediated to the nuclear rim by two components of PTAC58 and PTAC97. This findings support the idea that $\mathrm{Ku} 80$ can translocate to the nucleus using its own NLS independent of the translocation of Ku70 (Koike et al., 1999a). On the other hand, using the sitedirected mutagenesis technique, the same group demonstrated that $\mathrm{Ku} 70$ can also translocate to the nucleus without heterodimerization with Ku80 or independent of DNA-PK autophosphorylation (Koike et al., 2000).

The N-C or C-N translocation of DNA-PKcs is rarely reported. We have confirmed DNA-PKcs is not involved in Ku70-mediated IFN- $\lambda 1$ induction. Co-immunoprecipitation assay suggested DNA-PKcs is not present in the Ku70-STING complex. Therefore, implicating that DNA-PKcs does not translocate together with $\mathrm{Ku} 70$ or Ku80 from the nucleus to the cytoplasm upon a DNA transfection or DNA virus infection (Sui et al., 2017). Other factors may involve in facilitating the translocation of DNA-PKcs. Further study is required to help us understand the translocation of DNA-PKcs. 
Regulation of the N-C translocation has been defined as an essential mechanism to control protein activities. Whether some other cellular factors may facilitate $\mathrm{Ku} 70, \mathrm{Ku}$, or DNA-PK to respond to specific stimuli by regulating its nuclear or cytoplasmic localization remains to be identified. Better understanding the $\mathrm{N}-\mathrm{C}$ translocation of $\mathrm{Ku} 70, \mathrm{Ku} 80$ and DNA-PKcs may provide unique insights into the multiple functions of $\mathrm{Ku} 70$ in the DNA repair process, Bax-mediated apoptosis, and innate immune response.

In addition to regulating the $\mathrm{N}-\mathrm{C}$ transport, the detailed mechanisms regarding $\mathrm{Ku} 70$-mediated innate immunity offer multiple strategies to downregulate cytosolic DNA-induced autoimmunity or enhance innate immune response under the context of DNA vaccination. For example, Wang et al. found that the $\mathrm{Ku} 70 / \mathrm{Ku} 80$ heterodimer recognizes aging-related DNA accumulation in the cytoplasm of human or mouse $\mathrm{CD} 4^{+} \mathrm{T}$ cells. The sensing by the Ku complex further recruits DNA-PKs on the site and triggers the phosphorylation of ZAK. Subsequently, it activates the AKT-mTOR signaling pathway, which enhances the proliferation of $\mathrm{CD} 4^{+} \mathrm{T}$ cells and accelerates the pathology progress of experimental autoimmune encephalomyelitis (EAE) in mice (Wang et al., 2021). Consequently, based on the discovered molecular mechanism, the group further developed an inhibitor specific against ZAK to dampen the pathology progress of EAE (Wang et al., 2021).

It is known that many viruses possess the system to escape from the innate immune response by host cells. The mechanism of the immune escape by a DNA virus, Vaccinia virus (VACV), has been investigated (Bowie and Unterholzner, 2008; Elde et al., 2012). The
VACV C16 protein was reported as the first protein to inhibit DNAPK-mediated signaling (Peters et al., 2013). It has been demonstrated that the $\mathrm{C}$-terminal region of $\mathrm{C} 16$ binds directly to the Ku70/Ku80 complex, therefore blocking the sensing of $\mathrm{Ku}$ to DNA. The protein VACV C16 is not endogenously expressed on VACV strain Western Reserve. So the intranasal infection of this virus strain in mice leads to enhanced innate immune response and less symptoms of viral infection-related sickness (Fahy et al., 2008; Peters et al., 2013). Another protein of VACV, C4, is later identified targeting DNA-PK to inhibit DNA-PK-mediated signaling. VACV $\mathrm{C} 4$ possesses a similar sequence as $\mathrm{C} 16$, so it shares a similar mechanism to block DNA binding to DNA-PK by binding to the $\mathrm{Ku}$ complex. The absence of $\mathrm{C} 4$ promotes innate and adaptive immune responses (Scutts et al., 2018). Overall, these findings demonstrate that viral proteins help to evade the sensing of the viral genome by inhibiting the activity of PRR, therefore highlighting alternative strategies to regulate the innate immune response.

Similar to VACV, DNA virus HSV-1 has also shown the ability to evade innate immune responses in host cells ( $\mathrm{Su}$ et al., 2016; Lum and Cristea, 2021). Studies from Zheng's lab implicated that HSV-1 VP24, a serine protease, could also inhibit dsDNA-initiated IFN production by blocking the interaction between IRF3 and TBK1 and therefore dampening the phosphorylation of IRF3 (Zhang et al., 2016a). Another study demonstrated that HSV-1 VP16 could interrupt IRF3 recruiting the CREB-binding protein coactivator, thus inhibiting IRF3-mediated downstream signaling (Xing et al., 2013). Furthermore, US3 of HSV-1, another viral protein

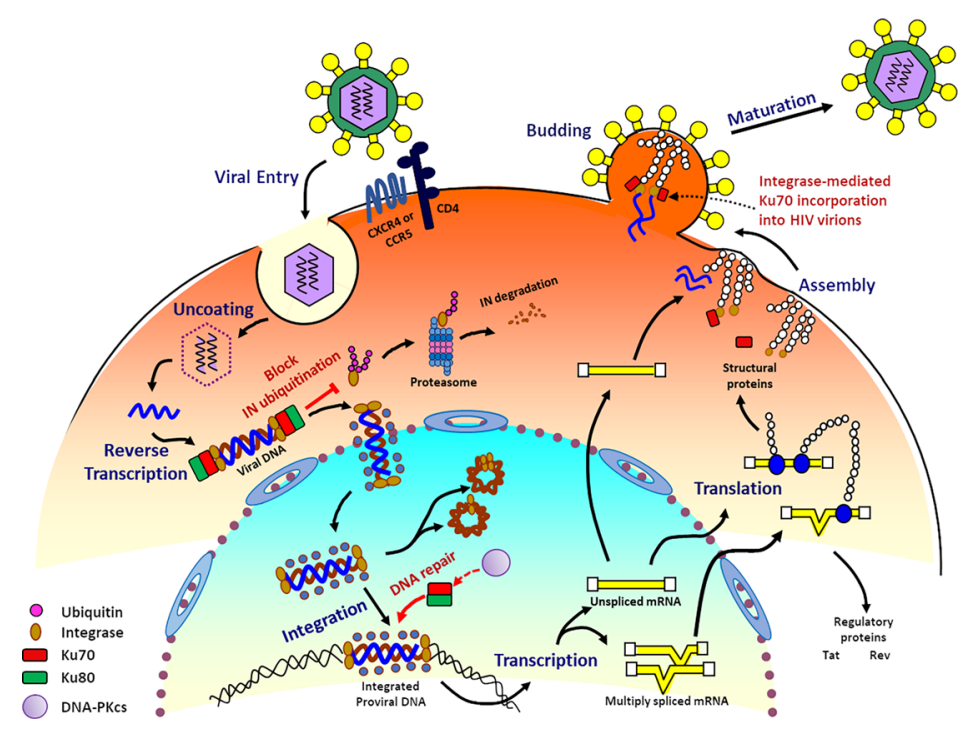

FIGURE 4 | Ku70 is an indispensable host cellular factor in the early and late stages of the HIV-1 replication cycle. The interaction of IN with Ku70 during HIV reverse transcription prevents IN from degradation by the K48-linked Ub proteasome pathway. The interaction between Ku70 and IN decreases the modification level of IN by Ub in the cells. During the integration step, the initial binding of Ku70 and HIV-1 IN facilitates the recruitment of other members of the DNA-PK complex to the post-integration site. Then Ku70 serves as a member of DNA-PK and participates in the DNA gaps repair process through the NHEJ pathway, thereby completing the integration of viral DNA into the cell genome and enabling the HIV-1 viral replication. Ku70 is also packaged into HIV particles as early as its assembly stage and becomes part of HIV virions, and this process is mediated by HIV IN. 
kinase, has been reported to prevent IRF3 activation and inhibit type-I IFN production by hyper phosphorylating IRF3 at Ser175 (Wang et al., 2013; Wang et al., 2014). It has been reported that HSV-1 ICP27 interacts with TBK1 and STING, which impairs the activation of downstream transcription factor IRF3. (Christensen et al., 2016). Our previous study also found that the Ku70-mediated type-III IFN response was induced in an HSV-1 strain-dependent manner: Infection with the HSV-1 McKrae strain triggers the cytoplasmic translocation of $\mathrm{Ku} 70$ and induces IFN- $\lambda 1$ induction, while infection with the HSV-1 MacIntyre strain does not. Therefore, we speculated that the HSV-1 MacIntyre strain might encode specific viral proteins that may inhibit the signaling pathway of IFN induction. Further studies are needed to identify the specific molecular mechanism for HSV-1 immune evasion. As we listed above, all these observations implicated that HSV-1-encoded viral proteins to facilitate HSV-1 immune evasion could interrupt the downstream signaling of DNA-mediated signaling pathway, therefore providing potential strategies to regulate any signaling pathway with shared downstream signaling adaptors, such as STING, TBK1, and IRF3.

In summary, with an aim to highlight innate immune response mediated by DNA virus infection in a battle against viral infection, a better understanding of the interplay between host innate immune response and viral immune evasion would provide intriguing novel strategies to help develop diverse therapies to treat viral infection-related diseases.

\section{BEYOND THE ROLE OF KU70 IN INNATE IMMUNITY: A ROLE OF KU70 IN HIV REPLICATION CYCLE AND BACTERIAL INTERNALIZATION}

HIV needs many cellular factors to facilitate its replication (EmigAgius et al., 2014). Ku70 and Ku80 are reported as host partners involving in HIV replication (Waninger et al., 2004; Studamire and Goff, 2008; Santos et al., 2012; Schweitzer et al., 2013; Emig-Agius et al., 2014; Hultquist et al., 2016; Li et al., 2016a). Several studies found that $\mathrm{Ku} 70 / \mathrm{Ku} 80$ heterodimer binds with HIV genomic RNA or TAR RNA at the 5' end of mRNA transcripts. Those data further implicated that the $\mathrm{Ku}$ complex may regulate the transcription process of HIV. (Kaczmarski and Khan, 1993; Yoo and Dynan, 1998); the interactions between Ku and HIV RNA may also impact the transcription level of HIV and the latency property of HIV (Manic et al., 2013). Additionally, $\mathrm{Ku}$ could also regulate transcriptional elongation by interacting with the RNA hairpin structure of 7SK snRNA, a scaffold protein for forming the 7SK snRNP complex (Shadrina et al., 2016; Shadrina et al., 2020). Several contradictory studies also show that Ku involves in retroviral DNA integration (Daniel et al., 1999; Baekelandt et al., 2000; Daniel et al., 2004; Knyazhanskaya et al., 2016) in the transcription of integrated provirus (Jeanson and Mouscadet, 2002; Tyagi et al., 2011; Manic et al., 2013; Shadrina et al., 2016), and in functions of HIV-1 matrix protein (Li et al., 2016a). Another evidence demonstrated that the DNA-PK complex involves in the induction of apoptosis in activated $\mathrm{CD} 4^{+} \mathrm{T}$ cells at the early stage of HIV infection (Cooper et al., 2013).

HIV-1 integrase (IN) is an essential viral enzyme involving in several viral replication steps. Meanwhile, IN is also an unstable protein and degraded by the $\mathrm{N}$-end rule pathway through the host ubiquitin-proteasome machinery (Mulder and Muesing, 2000). However, it remains unknown how HIV-1 IN is protected from degradation during HIV replication. Zheng et al. demonstrated that Ku70 from host cells interacts with HIV-1 IN and prevents it from the Lys48-linked polyubiquitination proteasomal pathway. Additionally, Ku70 can decrease the overall protein polyubiquitination level and specifically deubiquitinate IN by binding with HIV-1 IN (Zheng et al., 2011). Mutagenic studies by Anisenko et al. showed that the amino acid residues 51-160 of HIV-1 IN interacts with 251-438 aa of Ku70. It is further reported that the N-terminal region (1-250 aa) of Ku70 interacts with the $\alpha 6$-helix region located at the 200-220 residues of IN, and the single mutations at E212A or L213A abrogate the interaction. Those findings highlighted the essential role of the 200-220 aa residues of IN in forming a complex with $\mathrm{Ku} 70$ (Anisenko et al., 2017a).

Additionally, knockdown of Ku70 significantly inhibits the HIV-1 virus replication in virus-producing cell lines or HIVinfected CD4+ T cells, and the copy number of two-long terminal repeat (LTR) circles and integrated proviral DNA cannot be detected. Those data implicated that $\mathrm{Ku} 70$ is an indispensable factor at the early and the late stages of HIV-1 replication (Zheng et al., 2011) (as illustrated in Figure 4). HIV-1 IN is an essential enzyme in HIV virions and integrates the proviral DNA into the host genomic DNA. Integration is a critical step during HIV-1 replication. (Cherepanov et al., 2003; Faure et al., 2005; Passos et al., 2017). In detail, IN binds viral DNA and then catalyzes the cleavage of dinucleotides from both 3'-ends of viral DNA. The complex of 3'-processed viral DNA and IN helps recruit some other viral and cellular proteins as cofactors. Subsequently, the whole complex imports into the nucleus. The second step of integration happens in the nucleus of the host cells. IN inserts the processed viral DNA into one strand of the genomic DNA of host cells (Lesbats et al., 2016). This insertion leads to 5-nucleotide gaps (Vincent et al., 1990; Vink et al., 1990; Lesbats et al., 2016). As a result, 3'-ends of viral DNA are then covalently associated with the cellular DNA. However, an overhang is formed at the $5^{\prime}$-ends because of an unpaired dinucleotide (Knyazhanskaya et al., 2019). In order to complete the integration process, the intermediate product has to be repaired (Knyazhanskaya et al., 2016). Knyazhanskaya et al. proposed that the direct binding between Ku70 and HIV-1 IN greatly facilitates the recruitment of Ku80 and DNA-PKcs to the integration site. And then, the whole DNA-PK complex sufficiently functions in initiating the DNA repair process by the NHEJ pathway and resumes efficient HIV-1 replication (Knyazhanskaya et al., 2019).

Interestingly, Zheng et al. found that $\mathrm{Ku} 70$ is incorporated into HIV viral particles (Zheng et al., 2011). Nascent HIV viruses contain Gag and GagPol polyproteins, and viral genomic RNAs (as illustrated in Figure 4). The polyproteins are composed of several HIV proteins and immature forms of IN, located at 
the C'- terminus end (Imamichi et al., 2021). Thus, Ku70 maybe incorporated in the virion during assembly via the immature IN. As IN regulates viral maturation (Engelman et al., 1995; Bukovsky and Göttlinger, 1996; Balakrishnan et al., 2013; Hoyte et al., 2017; Imamichi et al., 2021). Further study may reveal more roles of $\mathrm{Ku} 70$ during retrovirus infection and replication.

Overall, many studies have provided examples of how HIV-1 viruses commandeer host cellular machinery to protect themselves and facilitate viral replication (Zheng et al., 2011). Consequently, identifying the host cell factors that participate in these processes and determining their functions in HIV viral replication may lead to discovering novel therapeutic targets to fight HIV (Adamson and Freed, 2010; Tintori et al., 2014). Ku70 may become an ideal therapeutic target to treat patients infected with multi-drug-resistant HIV variants.

As we discussed in the current review, cytosolic Ku70, which is translocated from the nucleus to the cytoplasm, can sense cytosolic DNA to induce innate immune response (Zhang et al., 2011a; Ferguson et al., 2012; Li et al., 2016b; Sui et al., 2017; Wang et al., 2017; Burleigh et al., 2020; Sui et al., 2021; Wang et al., 2021), and can inhibit Bax-mediated apoptosis (Sawada et al., 2003; Mazumder et al., 2007). Additionally, Ku70 has also been found localized in the plasma membrane, where it can interact with metalloprotease 9 (MMP-9) (Monferran et al., 2004b), fibronectin (Monferran et al., 2004a) and participate in heterologous and homologous cell adhesion (Koike, 2002). It was also reported that the cell-surfaced $\mathrm{Ku} 70$ acts as a receptor for the infection of Rickettsia conorii ( $R$. conorii), a negative gamma bacterium; the rickettsial protein, $\mathrm{rOmpB}$, binds to $\mathrm{Ku} 70$ as a ligand. The interaction plays an important role in initiating infection signals, ultimately leading to bacterial entry (Martinez et al., 2005). The plasma membrane-associated Ku70 has also been identified in lipid rafts, and so it has been speculated that the existence of $\mathrm{Ku} 70$ within these domains may play an essential role in pathogen entry and signal transduction (Lucero et al., 2003).

Beyond the role of $\mathrm{Ku} 70$ in innate immunity, those studies about the involvement of Ku70 in pathogen invasion and HIV replication highlighted a further understanding of the interplay between the host protein Ku70 and pathogen. Further investigation could lead to the development of novel, efficacious therapies in the treatment and prevention of infectious diseases.

\section{CONCLUSIONS AND PERSPECTIVES}

The study of Ku70/80 is expanding to encompass numerous research fields, including regulatory processes. More and more promising research emphasizes the role of $\mathrm{Ku}$ in innate immunity, the development of a small-molecule $\mathrm{Ku}$ inhibitor (Weterings et al., 2016), and the essential clinical relevance of Ku. Exploring the molecular mechanism by which the $\mathrm{Ku}$ - or DNA-PK-involved innate immune response confers various strategies to regulate innate immune cascade and could shed light on the role of Ku70 in autoimmune diseases, vaccine development, or aging-related abnormalities. Further investigation could lead to more discoveries at both the basic and translational research levels.
Delineation of the molecular mechanisms of Ku70-mediated innate immune response, especially the cytoplasmic translocation of $\mathrm{Ku} 70$, provides novel strategies to regulate innate immune cascades in response to the invasion of foreign microbe DNA or the accumulation of abnormal cellular DNA. Some autoimmune diseases are caused by the persistent induction of proinflammatory cytokines and IFNs. The emergence of mutations in some genes, including Trex1, RNase H, SAMHD1, and others (Crow et al., 2006a; Crow et al., 2006b; Rice et al., 2009; Crow et al., 2015) leads to the abnormal accumulation of cellular DNA. Those abnormal cytoplasmic DNAs serve as dangerous PAMPs and are recognized by potential PRRs in host cells, and then initiate continuous production of innate immune cytokines. Hypothetically, inhibition of the cytoplasmic translocation of DNA sensors, such as Ku70 and IFI16, with some small compounds is expected to abrogate the sensing of cytosolic DNA, therefore downregulating IFN response and providing effective interventions for these autoimmune diseases. Similar strategies may also be used to decrease the over-response of host cells to some viral infections (Sun et al., 2021).

Future research may reveal a more comprehensive understanding of the multiple roles of $\mathrm{Ku} 70$, especially in the field of Ku70-involved innate immune networks. These findings would help us solve some remaining questions: how Ku70 regulates its activities in the nucleus and the cytoplasm, and whether it is possible that Ku70 also serves as a nucleus DNA sensor like IFI16 (Kerur et al., 2011; Unterholzner and Bowie, 2011; Li et al., 2012; Dell'oste et al., 2014; Ansari et al., 2015; Roy et al., 2019). Overall, a better understanding of the multiple functions of Ku70 at both the cellular and organismal level would provide new insights into treatments of infectious diseases and autoimmune abnormalities.

\section{AUTHOR CONTRIBUTIONS}

HS and TI conceptualized the work and contributed to writing the manuscript. MH and WC contributed to homology modeling for human Ku70 and Ku80. All authors contributed to editing the manuscript and approved the submitted version.

\section{FUNDING}

This research was supported (in part) by the National Institute of Allergy and Infectious Diseases. This project has been funded in whole or in part with federal funds from the National Cancer Institute, National Institutes of Health, under Contract No. HHSN261200800001E.

\section{ACKNOWLEDGMENTS}

The authors thank Y. Sei for creating the illustration of the HIV life cycle. 


\section{REFERENCES}

Abbasi, S., Parmar, G., Kelly, R. D., Balasuriya, N., and Schild-Poulter, C. (2021). The Ku Complex: Recent Advances and Emerging Roles Outside of NonHomologous End-Joining. Cell Mol. Life Sci. 78 (10), 4589-4613. doi: 10.1007/ s00018-021-03801-1

Abdelbaqi, K., Di Paola, D., Rampakakis, E., and Zannis-Hadjopoulos, M. (2013). $\mathrm{Ku}$ Protein Levels, Localization and Association to Replication Origins in Different Stages of Breast Tumor Progression. J. Cancer 4, 358-370. doi: $10.7150 /$ jca. 6289

Adamson, C. S., and Freed, E. O. (2010). Novel Approaches to Inhibiting HIV-1 Replication. Antiviral Res. 85, 119-141. doi: 10.1016/j.antiviral.2009.09.009

Akira, S., Uematsu, S., and Takeuchi, O. (2006). Pathogen Recognition and Innate Immunity. Cell 124, 783-801. doi: 10.1016/j.cell.2006.02.015

Al-Emam, A., Arbon, D., and Kysela, B. (2014). Deacetylation of Ku70 Regulates Ionizing-Radiation Induced DNA Damage Responses in Human Cells. BMC Genomics 15, P24. doi: 10.1186/1471-2164-15-S2-P24

Anisenko, A. N., Knyazhanskaya, E. S., Zalevsky, A. O., Agapkina, J. Y., Sizov, A. I., Zatsepin, T. S., et al. (2017a). Characterization of HIV-1 Integrase Interaction With Human Ku70 Protein and Initial Implications for Drug Targeting. Sci. Rep. 7, 5649. doi: 10.1038/s41598-017-05659-5

Anisenko, A. N., Knyazhanskaya, E. S., Zatsepin, T. S., and Gottikh, M. B. (2017b). Human Ku70 Protein Binds Hairpin RNA and Double Stranded DNA Through Two Different Sites. Biochimie 132, 85-93. doi: 10.1016/ j.biochi.2016.11.001

Ank, N., and Paludan, S. R. (2009). Type III IFNs: New Layers of Complexity in Innate Antiviral Immunity. Biofactors 35, 82-87. doi: 10.1002/biof.19

Ank, N., West, H., Bartholdy, C., Eriksson, K., Thomsen, A. R., and Paludan, S. R. (2006). Lambda Interferon (IFN- $\lambda$ ), a Type III IFN, Is Induced by Viruses and IFNs and Displays Potent Antiviral Activity Against Select Virus Infections In Vivo. J. Virol. 80, 4501-4509. doi: 10.1128/JVI.80.9.4501-4509.2006

Ansari, M. A., Dutta, S., Veettil, M. V., Dutta, D., Iqbal, J., Kumar, B., et al. (2015). Herpesvirus Genome Recognition Induced Acetylation of Nuclear IFI16 Is Essential for Its Cytoplasmic Translocation, Inflammasome and IFN-? Responses. PLoS Pathog. 11, e1005019. doi: 10.1371/journal.ppat.1005019

Aravind, L., and Koonin, E. V. (2001). Prokaryotic Homologs of the Eukaryotic DNA-End-Binding Protein Ku, Novel Domains in the Ku Protein and Prediction of a Prokaryotic Double-Strand Break Repair System. Genome Res. 11 (8), 1365-1374. doi: 10.1101/gr.181001

Baekelandt, V., Claeys, A., Cherepanov, P., Clercq, E. D., Strooper, B. D., Nuttin, B., et al. (2000). DNA-Dependent Protein Kinase Is Not Required for Efficient Lentivirus Integration. J. Virol. 74 (23), 11278-11285. doi: 10.1128/ JVI.74.23.11278-11285.2000

Balakrishnan, M., Yant, S. R., Tsai, L., O'sullivan, C., Bam, R. A., Tsai, A., et al. (2013). Non-Catalytic Site HIV-1 Integrase Inhibitors Disrupt Core Maturation and Induce a Reverse Transcription Block in Target Cells. PLoS One 8, e74163. doi: 10.1371/journal.pone.0074163

Barber, G. N. (2011). Cytoplasmic DNA Innate Immune Pathways. Immunol. Rev. 243, 99-108. doi: 10.1111/j.1600-065X.2011.01051.x

Barnes, G., and Rio, D. (1997). DNA Double-Strand-Break Sensitivity, DNA Replication, and Cell Cycle Arrest Phenotypes of Ku-Deficient Saccharomyces Cerevisiae. Proc. Nat. Acad. Sci. 94 (3), 867-872. doi: 10.1073/pnas.94.3.867

Bassing, C. H., Swat, W., and Alt, F. W. (2002). The Mechanism and Regulation of Chromosomal V(D)J Recombination. Cell 109, S45-S55. doi: 10.1016/S00928674(02)00675-X

Bertuch, A. A., and Lundblad, V. (2003). The Ku Heterodimer Performs Separable Activities at Double-Strand Breaks and Chromosome Termini. Mol. Cell. Biol. 23 (22), 8202-8215. doi: 10.1128/MCB.23.22.8202-8215.2003

Beutler, B. A. (2009). TLRs and Innate Immunity. Blood 113, 1399-1407. doi: 10.1182/blood-2008-07-019307

Biasini, M., Bienert, S., Waterhouse, A., Arnold, K., Studer, G., Schmidt, T., et al. (2014). SWISS-MODEL: Modelling Protein Tertiary and Quaternary Structure Using Evolutionary Information. Nucleic Acids Res. 42, W252-W258. doi: 10.1093/nar/gku340

Blackford, A. N., and Jackson, S. P. (2017). ATM, ATR, and DNA-PK: The Trinity at the Heart of the DNA Damage Response. Mol. Cell 66, 801-817. doi: 10.1016/j.molcel.2017.05.015
Blier, P. R., Griffith, A. J., Craft, J., and Hardin, J. A. (1993). Binding of Ku Protein to DNA. Measurement of Affinity for Ends and Demonstration of Binding to Nicks. J. Biol. Chem. 268, 7594-7601. doi: 10.1016/S0021-9258(18)53216-6

Booth, D., and George, J. (2013). Loss of Function of the New Interferon IFN- $\lambda 4$ May Confer Protection From Hepatitis C. Nat. Genet. 45, 119-120. doi: 10.1038/ng.2537

Bowater, R., and Doherty, A. J. (2006). Making Ends Meet: Repairing Breaks in Bacterial DNA by Non-Homologous End-Joining. PLoS Genet. 2, e8. doi: 10.1371/journal.pgen.0020008

Bowie, A. G., and Haga, I. R. (2005). The Role of Toll-Like Receptors in the Host Response to Viruses. Mol. Immunol. 42, 859-867. doi: 10.1016/ j.molimm.2004.11.007

Bowie, A. G., and Unterholzner, L. (2008). Viral Evasion and Subversion of Pattern-Recognition Receptor Signalling. Nat. Rev. Immunol. 8, 911-922. doi: $10.1038 /$ nri2436

Bukovsky, A., and Göttlinger, H. (1996). Lack of Integrase can Markedly Affect Human Immunodeficiency Virus Type 1 Particle Production in the Presence of an Active Viral Protease. J. Virol. 70, 6820-6825. doi: 10.1128/jvi.70.10.68206825.1996

Bunch, H., Lawney, B. P., Lin, Y.-F., Asaithamby, A., Murshid, A., Wang, Y. E., et al. (2015). Transcriptional Elongation Requires DNA Break-Induced Signalling. Nat. Commun. 6, 10191. doi: 10.1038/ncomms10191

Burckstuummer, T. (2009). An Orthogonal Proteomic-Genomic Screen Identifies AIM2 as a Cytoplasmic DNA Sensor for the Inflammasome. Nat. Immunol. 10, 266-272. doi: 10.1038/ni.1702

Burleigh, K., Maltbaek, J. H., Cambier, S., Green, R., Gale, M., James, R. C., et al. (2020). Human DNA-PK Activates a STING-Independent DNA Sensing Pathway. Sci. Immunol. 5, eaba4219. doi: 10.1126/sciimmunol.aba4219

Cai, X., Chiu, Y.-H., and Chen, ,. Z. J. (2014). The cGAS-cGAMP-STING Pathway of Cytosolic DNA Sensing and Signaling. Mol. Cell 54, 289-296. doi: 10.1016/ j.molcel.2014.03.040

Chaplin, A. K., Hardwick, S. W., Liang, S., Kefala Stavridi, A., Hnizda, A., Cooper, L. R., et al. (2021). Dimers of DNA-PK Create a Stage for DNA Double-Strand Break Repair. Nat. Struct. Mol. Biol. 28, 13-19. doi: 10.1038/s41594-02000517-x

Chaudhary, N., Nakka, K. K., Chavali, P. L., Bhat, J., Chatterjee, S., and Chattopadhyay, S. (2014). SMAR1 Coordinates HDAC6-Induced Deacetylation of Ku70 and Dictates Cell Fate Upon Irradiation. Cell Death Dis. 5, e1447-e1447. doi: 10.1038/cddis.2014.397

Cherepanov, P., Maertens, G., Proost, P., Devreese, B., Van Beeumen, J., Engelborghs, Y., et al. (2003). HIV-1 Integrase Forms Stable Tetramers and Associates With LEDGF/p75 Protein in Human Cells. J. Biol. Chem. 278, $372-$ 381. doi: 10.1074/jbc.M209278200

Christensen, M. H., Jensen, S. B., Miettinen, J. J., Luecke, S., Prabakaran, T., Reinert, L. S., et al. (2016). HSV-1 ICP27 Targets the TBK1-Activated STING Signalsome to Inhibit Virus-Induced Type I IFN Expression. EMBO J. 35 (13), 1385-1399. doi: 10.15252/embj.201593458

Christensen, M. H., and Paludan, S. R. (2016). Viral Evasion of DNA-Stimulated Innate Immune Responses. Cell. Mol. Immunol. 14, 4. doi: 10.1038/cmi.2016.06

Coccia, E. M., Severa, M., Giacomini, E., Monneron, D., Remoli, M. E., Julkunen, I., et al. (2004). Viral Infection and Toll-Like Receptor Agonists Induce a Differential Expression of Type I and $\lambda$ Interferons in Human Plasmacytoid and Monocyte-Derived Dendritic Cells. Eur. J. Immunol. 34, 796-805. doi: 10.1002/eji.200324610

Cohen, H. Y., Lavu, S., Bitterman, K. J., Hekking, B., Imahiyerobo, T. A., Miller, C., et al. (2004). Acetylation of the C Terminus of Ku70 by CBP and PCAF Controls Bax-Mediated Apoptosis. Mol. Cell 13, 627-638. doi: 10.1016/S10972765(04)00094-2

Cooper, A., Garcia, M., Petrovas, C., Yamamoto, T., Koup, R. A., and Nabel, G. J. (2013). HIV-1 Causes CD4 Cell Death Through DNA-Dependent Protein Kinase During Viral Integration. Nature 498, 376-379. doi: 10.1038/nature12274

Cosgrove, A. J., Nieduszynski, C. A., and Donaldson, A. D. (2002). Ku Complex Controls the Replication Time of DNA in Telomere Regions. Genes Dev. 16 (19), 2485-2490. doi: 10.1101/gad.231602

Critchlow, S. E., and Jackson, S. P. (1998). DNA End-Joining: From Yeast to Man. Trends Biochem. Sci. 23, 394-398. doi: 10.1016/S0968-0004(98)01284-5

Crow, Y. J., Chase, D. S., Lowenstein Schmidt, J., Szynkiewicz, M., Forte, G. M. A., Gornall, H. L., et al. (2015). Characterization of Human Disease Phenotypes 
Associated With Mutations in TREX1, RNASEH2A, RNASEH2B, RNASEH2C, SAMHD1, ADAR, and IFIH1. Am. J. Med. Genet. Part A 167, 296-312. doi: 10.1002/ajmg.a.36887

Crow, Y. J., Hayward, B. E., Parmar, R., Robins, P., Leitch, A., Ali, M., et al. (2006a). Mutations in the Gene Encoding the $3^{\prime}-5^{\prime}$ DNA Exonuclease TREX1 Cause Aicardi-Goutières Syndrome at the AGS1 Locus. Nat. Genet. 38, 917920. doi: $10.1038 /$ ng1845

Crow, Y. J., Leitch, A., Hayward, B. E., Garner, A., Parmar, R., Griffith, E., et al. (2006b). Mutations in Genes Encoding Ribonuclease H2 Subunits Cause Aicardi-Goutières Syndrome and Mimic Congenital Viral Brain Infection. Nat. Genet. 38 (8), 910-916. doi: 10.1038/ng1842

Daniel, R., Greger, J. G., Katz, R. A., Taganov, K. D., Wu, X., Kappes, J. C., et al. (2004). Evidence That Stable Retroviral Transduction and Cell Survival Following DNA Integration Depend on Components of the Nonhomologous End Joining Repair Pathway. J. Virol. 78 (16), 8573-8581. doi: 10.1128/ JVI.78.16.8573-8581.2004

Daniel, R., Katz, R. A., and Skalka, A. M. (1999). A Role for DNA-PK in Retroviral DNA Integration. Science 284 (5414), 644-647. doi: 10.1126/science.284. 5414.644

Davis, A. J., Lee, K.-J., and Chen, D. J. (2013). The N-Terminal Region of the DNA-Dependent Protein Kinase Catalytic Subunit Is Required for Its DNA Double-Stranded Break-Mediated Activation*. J. Biol. Chem. 288, 7037-7046. doi: 10.1074/jbc.M112.434498

Dell'oste, V., Gatti, D., Gugliesi, F., De Andrea, M., Bawadekar, M., Lo Cigno, I., et al. (2014). Innate Nuclear Sensor IFI16 Translocates Into the Cytoplasm During the Early Stage of In Vitro Human Cytomegalovirus Infection and Is Entrapped in the Egressing Virions During the Late Stage. J. Virol. 88, 69706982. doi: 10.1128/JVI.00384-14

Dempsey, A., and Bowie, A. G. (2015). Innate Immune Recognition of DNA: A Recent History. Virology 479-480, 146-152. doi: 10.1016/j.virol.2015.03.013

Dobbs, T. A., Tainer, J. A., and Lees-Miller, S. P. (2010). A Structural Model for Regulation of NHEJ by DNA-PKcs Autophosphorylation. DNA Repair 9, 1307-1314. doi: 10.1016/j.dnarep.2010.09.019

Doherty, A. J., and Jackson, S. P. (2001). DNA Repair: How Ku Makes Ends Meet. Curr. Biol. 11, R920-R924. doi: 10.1016/S0960-9822(01)00555-3

Donnelly, R. P., and Kotenko, S. V. (2010). Interferon-Lambda: A New Addition to an Old Family. J. Interferon Cytokine Res. 30, 555-564. doi: 10.1089/ jir.2010.0078

Dutertre, M., and Vagner, S. (2017). DNA-Damage Response RNA-Binding Proteins (DDRBPs): Perspectives From a New Class of Proteins and Their RNA Targets. J. Mol. Biol. 429, 3139-3145. doi: 10.1016/j.jmb.2016.09.019

Dynan, W. S., and Yoo, S. (1998). Interaction of Ku Protein and DNA-Dependent Protein Kinase Catalytic Subunit With Nucleic Acids. Nucleic Acids Res. 26, 1551-1559. doi: 10.1093/nar/26.7.1551

Elde, N. C., Child, S. J., Eickbush, M. T., Kitzman, J. O., Rogers, K. S., Shendure, J., et al. (2012). Poxviruses Deploy Genomic Accordions to Adapt Rapidly Against Host Antiviral Defenses. Cell 150, 831-841. doi: 10.1016/ j.cell.2012.05.049

Emig-Agius, D., Olivieri, K., Pache, L., Shih, H. L., Pustovalova, O., Bessarabova, M., et al. (2014). An Integrated Map of HIV-Human Protein Complexes That Facilitate Viral Infection. PLoS One 9, e96687. doi: 10.1371/ journal.pone.0096687

Engelman, A., Englund, G., Orenstein, J. M., Martin, M. A., and Craigie, R. (1995). Multiple Effects of Mutations in Human Immunodeficiency Virus Type 1 Integrase on Viral Replication. J. Virol. 69, 2729-2736. doi: 10.1128/ jvi.69.5.2729-2736.1995

Errami, A., Smider, V., Rathmell, W. K., He, D. M., Hendrickson, E. A., Zdzienicka, M. Z., et al. (1996). Ku86 Defines the Genetic Defect and Restores X-Ray Resistance and V(D)J Recombination to Complementation Group 5 Hamster Cell Mutants. Mol. Cell Biol. 16, 1519-1526. doi: 10.1128/ MCB.16.4.1519

Fahy, A. S., Clark, R. H., Glyde, E. F., and Smith, G. L. (2008). Vaccinia Virus Protein C16 Acts Intracellularly to Modulate the Host Response and Promote Virulence. J. Gen. Virol. 89 (Pt 10), 2377-2387. doi: 10.1099/ vir.0.2008/004895-0

Faure, A., Calmels, C., Desjobert, C., Castroviejo, M., Caumont-Sarcos, A., Tarrago-Litvak, L., et al. (2005). HIV-1 Integrase Crosslinked Oligomers Are Active In Vitro. Nucleic Acids Res. 33, 977-986. doi: 10.1093/nar/gki241
Fell, V. L., and Schild-Poulter, C. (2012). Ku Regulates Signaling to DNA Damage Response Pathways Through the Ku70 Von Willebrand A Domain. Mol. Cell. Biol. 32 (1), 76-87. doi: 10.1128/MCB.05661-11

Fell, V. L., and Schild-Poulter, C. (2015). The Ku Heterodimer: Function in DNA Repair and Beyond. Mutat. Res/Rev Mutat. Res. 763, 15-29. doi: 10.1016/ j.mrrev.2014.06.002

Ferguson, B. J., Mansur, D. S., Peters, N. E., Ren, H., and Smith, G. L. (2012). DNA-PK Is a DNA Sensor for IRF-3-Dependent Innate Immunity. Elife 1, e00047. doi: 10.7554/eLife.00047

Fernandes-Alnemri, T., Yu, J. W., Datta, P., Wu, J., and Alnemri, E. S. (2009). AIM2 Activates the Inflammasome and Cell Death in Response to Cytoplasmic DNA. Nature 458, 509-513. doi: 10.1038/nature07710

Foster, S. S., Balestrini, A., and Petrini, J. H. J. (2011). Functional Interplay of the Mre11 Nuclease and $\mathrm{Ku}$ in the Response to Replication-Associated DNA Damage. Mol. Cell. Biol. 31 (21), 4379-4389. doi: 10.1128/MCB.05854-11

Fugmann, S. D., Lee, A. I., Shockett, P. E., Villey, I. J., and Schatz, D. G. (2000). The RAG Proteins and V(D)J Recombination: Complexes, Ends, and Transposition. Annu. Rev. Immunol. 18, 495-527. doi: 10.1146/annurev. immunol.18.1.495

Fujimoto, H., Ikuta, T., Koike, A., and Koike, M. (2018). Acetylation of Nuclear Localization Signal Controls Importin-Mediated Nuclear Transport of Ku70. bioRxiv. doi: $10.1101 / 403485$

Gao, D., Wu, J., Wu, Y.-T., Du, F., Aroh, C., Yan, N., et al. (2013). Cyclic GMPAMP Synthase Is an Innate Immune Sensor of HIV and Other Retroviruses. Science 341, 903-906. doi: 10.1126/science. 1240933

Gell, D., and Jackson, S. P. (1999). Mapping of Protein-Protein Interactions Within the DNA-Dependent Protein Kinase Complex. Nucleic Acids Res. 27, 3494-3502. doi: 10.1093/nar/27.17.3494

Giffin, W., Kwast-Welfeld, J., Rodda, D. J., Préfontaine, G. G., TraykovaAndonova, M., Zhang, Y., et al. (1997). Sequence-Specific DNA Binding and Transcription Factor Phosphorylation by Ku Autoantigen/DNA-Dependent Protein Kinase: PHOSPHORYLATION OF Ser-527 OF THE RAT GLUCOCORTICOID RECEPTOR*. J. Biol. Chem. 272, 5647-5658. doi: $10.1074 / \mathrm{jbc} .272 .9 .5647$

Giffin, W., Torrance, H., Rodda, D. J., Préfontaine, G. G., Pope, L., and Haché, R. J. G. (1996). Sequence-Specific DNA Binding by Ku Autoantigen and Its Effects on Transcription. Nature 380, 265-268. doi: 10.1038/380265a0

Göhring, F., Schwab, B. L., Nicotera, P., Leist, M., and Fackelmayer, F. O. (1997). The Novel SAR-Binding Domain of Scaffold Attachment Factor A (SAF-A) Is a Target in Apoptotic Nuclear Breakdown. EMBO J. 16 (24), 7361-7371. doi: $10.1093 / \mathrm{emboj} / 16.24 .7361$

Gomez, J. A., Gama, V., Yoshida, T., Sun, W., Hayes, P., Leskov, K., et al. (2007). Bax-Inhibiting Peptides Derived From Ku70 and Cell-Penetrating Pentapeptides. Biochem. Soc. Trans. 35, 797-801. doi: 10.1042/BST0350797

Gong, P., Wang, Y., and Jing, Y. (2019). Apoptosis Induction Byhistone Deacetylase Inhibitors in Cancer Cells: Role of Ku70. Int. J. Mol. Sci. 20 (7), 1601. doi: $10.3390 /$ ijms 20071601

Görlich, D., and Mattaj, I. W. (1996). Nucleocytoplasmic Transport. Science 271 (5255), 1513-1519. doi: 10.1126/science.271.5255.1513

Grundy, G. J., Rulten, S. L., Zeng, Z., Arribas-Bosacoma, R., Iles, N., Manley, K., et al. (2013). APLF Promotes the Assembly and Activity of Non-Homologous End Joining Protein Complexes. Embo J. 32 (1), 112-125. doi: 10.1038/ emboj.2012.304

Gu, Y., Jin, S., Gao, Y., Weaver, D. T., and Alt, F. W. (1997). Ku70Deficient Embryonic Stem Cells Have Increased Ionizing Radiosensitivity, Defective DNA End-Binding Activity, and Inability to Support V(D) J recombination. Proc. Natl. Acad. Sci. 94, 8076-8081. doi: 10.1073/pnas.94. 15.8076

Hammarsten, O., and Chu, G. (1998). DNA-Dependent Protein Kinase: DNA Binding and Activation in the Absence of Ku. Proc. Natl. Acad. Sci. 95, 525530. doi: $10.1073 /$ pnas. 95.2 .525

Harper, J. W., and Elledge, S. J. (2007). The DNA Damage Response: Ten Years After. Mol. Cell 28, 739-745. doi: 10.1016/j.molcel.2007.11.015

Hornung, V. (2009). AIM2 Recognizes Cytosolic dsDNA and Forms a Caspase-1Activating Inflammasome With ASC. Nature 458, 514-518. doi: 10.1038/ nature 07725

Hoyte, A. C., Jamin, A. V., Koneru, P. C., Kobe, M. J., Larue, R. C., Fuchs, J. R., et al. (2017). Resistance to Pyridine-Based Inhibitor KF116 Reveals 
an Unexpected Role of Integrase in HIV-1 Gag-Pol Polyprotein Proteolytic Processing. J. Biol. Chem. 292, 19814-19825. doi: 10.1074/ jbc.M117.816645

Hultquist, J. F., Schumann, K., Woo, J. M., Manganaro, L., Mcgregor, M. J., Doudna, J., et al. (2016). A Cas9 Ribonucleoprotein Platform for Functional Genetic Studies of HIV-Host Interactions in Primary Human T Cells. Cell Rep. 17, 1438-1452. doi: 10.1016/j.celrep.2016.09.080

Imamichi, T., Bernbaum, J. G., Laverdure, S., Yang, J., Chen, Q., Highbarger, H., et al. (2021). Natural Occurring Polymorphisms in HIV-1 Integrase and RNase H Regulate Viral Release and Autoprocessing. J. Virol. Jvi0132321. doi: 10.1128/jvi.01323-21

Indiviglio, S. M., and Bertuch, A. A. (2009). Ku's Essential Role in Keeping Telomeres Intact. Proc. Natl. Acad. Sci. U. S. A. 106 (30), 12217-12218. doi: 10.1073/pnas.0906427106

Jackson, S. P., and Bartek, J. (2009). The DNA-Damage Response in Human Biology and Disease. Nature 461, 1071-1078. doi: 10.1038/nature08467

Jackson, S. P., and Jeggo, P. A. (1995). DNA Double-Strand Break Repair and V (D)J Recombination: Involvement of DNA-PK. Trends Biochem. Sci. 20, 412415. doi: 10.1016/S0968-0004(00)89090-8

Jeanson, L., and Mouscadet, J.-F. (2002). Ku Represses the HIV-1 Transcription: Identification of a Putative $\mathrm{Ku}$ Binding Site Homologous to the Mouse Mammary Tumor Virus Nre1 Sequence in the HIV-1 Long Terminal Repeat*. J. Biol. Chem. 277, 4918-4924. doi: 10.1074/jbc.M110830200

Kaczmarski, W., and Khan, S. A. (1993). Lupus Autoantigen Ku Protein Binds HIV-1 TAR RNA In Vitro. Biochem. Biophys. Res. Commun. 196, 935-942. doi: 10.1006/bbrc. 1993.2339

Kaisho, T., and Akira, S. (2006). Toll-Like Receptor Function and Signaling. J. Allergy Clin. Immunol. 117, 979-987. doi: 10.1016/j.jaci.2006.02.023

Kawai, T., and Akira, S. (2009). The Roles of TLRs, RLRs and NLRs in Pathogen Recognitionint. Int. Immunol. 21 (4), 317-337. doi: 10.1093/intimm/dxp017

Keating, S. E., Baran, M., and Bowie, A. G. (2011). Cytosolic DNA Sensors Regulating Type I Interferon Induction. Trends Immunol. 32, 574-581. doi: 10.1016/j.it.2011.08.004

Keijzers, G. (2018). "Ku70 and Ku80," in Encyclopedia of Signaling Molecules. Ed. S. Choi (Cham: Springer International Publishing), 2781-2786.

Kerur, N., Veettil, M.V., Sharma-Walia, N., Bottero, V., Sadagopan, S., Otageri, P., et al. (2011). IFI16 Acts as a Nuclear Pathogen Sensor to Induce the Inflammasome in Response to Kaposi Sarcoma-Associated Herpesvirus Infection. Cell Host Microbe 9, 363-375. doi: 10.1016/j.chom.2011.04.008

Kim, K.-B., Kim, D.-W., Park, J. W., Jeon, Y.-J., Kim, D., Rhee, S., et al. (2014). Inhibition of Ku70 Acetylation by INHAT Subunit SET/TAF-I $\beta$ Regulates Ku70-Mediated DNA Damage Response. Cell. Mol. Life Sci. 71, 2731-2745. doi: 10.1007/s00018-013-1525-8

Kim, T., Pazhoor, S., Bao, M., Zhang, Z., Hanabuchi, S., Facchinetti, V., et al. (2010). Aspartate-Glutamate-Alanine-Histidine Box Motif (DEAH)/RNA Helicase A Helicases Sense Microbial DNA in Human Plasmacytoid Dendritic Cells. Proc. Natl. Acad. Sci. 107, 15181-15186. doi: 10.1073/pnas.1006539107

Knyazhanskaya, E., Anisenko, A., Shadrina, O., Kalinina, A., Zatsepin, T., Zalevsky, A., et al. (2019). NHEJ Pathway Is Involved in Post-Integrational DNA Repair Due to Ku70 Binding to HIV-1 Integrase. Retrovirology 16, 30. doi: 10.1186/s12977-019-0492-z

Knyazhanskaya, E. S., Shadrina, O. A., Anisenko, A. N., and Gottikh, M. B. (2016). Role of DNA-Dependent Protein Kinase in the HIV-1 Replication Cycle. Mol. Biol. 50, 567-579. doi: 10.1134/\$0026893316040075

Koike, M. (2002). Dimerization, Translocation and Localization of Ku70 and Ku80 Proteins. J. Radiat. Res. 43, 223-236. doi: 10.1269/jrr.43.223

Koike, M., Ikuta, T., Miyasaka, T., and Shiomi, T. (1999a). Ku80 can Translocate to the Nucleus Independent of the Translocation of Ku70 Using Its Own Nuclear Localization Signal. Oncogene 18, 7495-7505. doi: 10.1038/ sj.onc. 1203247

Koike, M., Ikuta, T., Miyasaka, T., and Shiomi, T. (1999b). The Nuclear Localization Signal of the Human Ku70 Is a Variant Bipartite Type Recognized by the Two Components of Nuclear Pore-Targeting Complex. Exp. Cell Res. 250, 401-413. doi: 10.1006/excr.1999.4507

Koike, M., Shiomi, T., and Koike, A. (2000). Ku70 Can Translocate to the Nucleus Independent of Ku80 Translocation and DNA-PK Autophosphorylation. Biochem. Biophys. Res. Commun. 276, 1105-1111. doi: $10.1006 /$ bbrc. 2000.3567
Koike, M., Yutoku, Y., and Koike, A. (2017). Cloning of Canine Ku80 and Its Localization and Accumulation at DNA Damage Sites. FEBS Open Bio 7, 18541863. doi: 10.1002/2211-5463.12311

Kotenko, S. V. (2011). IFN- $\lambda$ s. Curr. Opin. Immunol. 23, 583-590. doi: 10.1016/ j.coi.2011.07.007

Kotenko, S. V., Gallagher, G., Baurin, V. V., Lewis-Antes, A., Shen, M., Shah, N. K., et al. (2003). IFN- $\lambda$ s Mediate Antiviral Protection Through a Distinct Class II Cytokine Receptor Complex. Nat. Immunol. 4, 69-77. doi: 10.1038/ni875

Lamaa, A., Le Bras, M., Skuli, N., Britton, S., Frit, P., Calsou, P., et al. (2016). A Novel Cytoprotective Function for the DNA Repair Protein Ku in Regulating P53 mRNA Translation and Function. EMBO Rep. 17 (4), 508-518. doi: 10.15252/embr.201541181

Lee, M. S., and Kim, Y.-J. (2007). Signaling Pathways Downstream of PatternRecognition Receptors and Their Cross Talk. Annu. Rev. Biochem. 76, 447480. doi: 10.1146/annurev.biochem.76.060605.122847

Lesbats, P., Engelman, A. N., and Cherepanov, P. (2016). Retroviral DNA Integration. Chem. Rev. 116, 12730-12757. doi: 10.1021/acs.chemrev.6b00125

Li, T., Diner, B. A., Chen, J., and Cristea, I. M. (2012). Acetylation Modulates Cellular Distribution and DNA Sensing Ability of Interferon-Inducible Protein IFI16. Proc. Natl. Acad. Sci. 109, 10558-10563. doi: 10.1073/pnas. 1203447109

Li, Y., Frederick, K. M., Haverland, N. A., Ciborowski, P., and Belshan, M. (2016a). Investigation of the HIV-1 Matrix Interactome During Virus Replication. Prot. Clin. Appl. 10 (2), 156-163. doi: 10.1002/prca.201400189

Li, Y., Wu, Y., Zheng, X., Cong, J., Liu, Y., Li, J., et al. (2016b). CytoplasmTranslocated Ku70/80 Complex Sensing of HBV DNA Induces HepatitisAssociated Chemokine Secretion. Front. Immunol. 7, 569. doi: 10.3389/ fimmu. 2016.00569

Li, G. C., Yang, S. H., Kim, D., Nussenzweig, A., Ouyang, H., Wei, J., et al. (1995). Suppression of Heat-Induced Hsp70 Expression by the $70-\mathrm{kDa}$ Subunit of the Human Ku Autoantigen. Proc. Natl. Acad Sci. U. S. A. 92 (10), 4512-4516. doi: $10.1073 /$ pnas.92.10.4512

Lucero, H., Gae, D., and Taccioli, G. E. (2003). Novel Localization of the DNA-PK Complex in Lipid Rafts: A Putative Role in the Signal Transduction Pathway of the Ionizing Radiation Response. J. Biol. Chem. 278, 22136-22143. doi: 10.1074/jbc.M301579200

Lu, Y.-F., Goldstein, D. B., Urban, T. J., and Bradrick, S. S. (2015). Interferon- $\lambda 4$ Is a Cell-Autonomous Type III Interferon Associated With Pre-Treatment Hepatitis C Virus Burden. Virology 476, 334-340. doi: 10.1016/ j.virol.2014.12.020

Lum, K., and Cristea, I. (2021). Host Innate Immune Response and Viral Immune Evasion During Alphaherpesvirus Infection. Curr. Issues Mol. Biol. 42, 635686. doi: $10.21775 / \mathrm{cimb} .042 .635$

Makowski, M. M., Willems, E., Jansen, P. W. T. C., and Vermeulen, M. (2016). Cross-Linking Immunoprecipitation-MS (xIP-MS): Topological Analysis of Chromatin-Associated Protein Complexes Using Single Affinity Purification* Mol. Cell. Proteomics 15, 854-865. doi: 10.1074/mcp.M115.053082

Manic, G., Maurin-Marlin, A., Laurent, F., Vitale, I., Thierry, S., Delelis, O., et al. (2013). Impact of the Ku Complex on HIV-1 Expression and Latency. PLoS One 8, e69691. doi: 10.1371/journal.pone.0069691

Martinez, J. J., Seveau, S., Veiga, E., Matsuyama, S., and Cossart, P. (2005). Ku70, a Component of DNA-Dependent Protein Kinase, Is a Mammalian Receptor for Rickettsia conorii. Cell 123, 1013-1023. doi: 10.1016/j.cell.2005.08.046

Matheos, D., Ruiz, M. T., Price, G. B., and Zannis-Hadjopoulos, M. (2002). Ku Antigen, an Origin-Specific Binding Protein That Associates With Replication Proteins, Is Required for Mammalian DNA Replication. Biochim. Biophys. Acta (BBA) Gene Structure Expression 1578, 59-72. doi: 10.1016/S0167-4781 (02)00497-9

Mazumder, S., Plesca, D., Kinter, M., and Almasan, A. (2007). Interaction of a Cyclin E Fragment With Ku70 Regulates Bax-Mediated Apoptosis. Mol. Cell. Biol. 27 (9), 3511-3520. doi: 10.1128/MCB.01448-06

Medzhitov, R., and Janeway, C. (1997). Innate Immunity: The Virtues of a Nonclonal System of Recognition. Cell 91, 295-298. doi: 10.1016/S0092-8674 (00)80412-2

Medzhitov, R., and Janeway, C. (2000). Innate Immunity. N. Engl. J. Med. 343, 338-344. doi: 10.1056/NEJM200008033430506

Menon, V., and Povirk, L. F. (2016). End-Processing Nucleases and Phosphodiesterases: An Elite Supporting Cast for the Non-Homologous End 
Joining Pathway of DNA Double-Strand Break Repair. DNA Repair 43, 57-68. doi: 10.1016/j.dnarep.2016.05.011

Mimori, T., Akizuki, M., Yamagata, H., Inada, S., Yoshida, S., and Homma, M. (1981). Characterization of a High Molecular Weight Acidic Nuclear Protein Recognized by Autoantibodies in Sera From Patients With PolymyositisScleroderma Overlap. J. Clin. Invest. 68, 611-620. doi: 10.1172/JCI110295

Miyoshi, T., Kanoh, J., and Ishikawa, F. (2009). Fission Yeast Ku Protein Is Required for Recovery From DNA Replication Stress. Genes Cells 14 (9), 10911103. doi: 10.1111/j.1365-2443.2009.01337.x

Mo, X., and Dynan, W. S. (2002). Subnuclear Localization of Ku Protein: Functional Association With RNA Polymerase II Elongation Sites. Mol. Cell. Biol. 22 (22), 8088-8099. doi: 10.1128/MCB.22.22.8088-8099.2002

Mogensen, T. H. (2009). Pathogen Recognition and Inflammatory Signaling in Innate Immune Defenses. Clin. Microbiol. Rev. 22, 240-273. doi: 10.1128/ CMR.00046-08

Monferran, S., Muller, C., Mourey, L., Frit, P., and Salles, B. (2004a). The Membrane-Associated Form of the DNA Repair Protein Ku Is Involved in Cell Adhesion to Fibronectin. J. Mol. Biol. 337, 503-511. doi: 10.1016/ j.jmb.2004.01.057

Monferran, S., Paupert, J., Dauvillier, S., Salles, B., and Muller, C. (2004b). The Membrane Form of the DNA Repair Protein Ku Interacts at the Cell Surface With Metalloproteinase 9. EMBO J. 23, 3758-3768. doi: 10.1038/ sj.emboj.7600403

Monroe, K. M., Yang, Z., Johnson, J. R., Geng, X., Doitsh, G., Krogan, N. J., et al. (2014). IFI16 DNA Sensor Is Required for Death of Lymphoid CD4 T Cells Abortively Infected With HIV. Science 343, 428-432. doi: 10.1126/ science. 1243640

Mulder, L. C. F., and Muesing, M. A. (2000). Degradation of HIV-1 Integrase by the N-End Rule Pathway *. J. Biol. Chem. 275, 29749-29753. doi: 10.1074/ jbc.M004670200

Novac, O., Matheos, D., Araujo, F. D., Price, G. B., and Zannis-Hadjopoulos, M. (2001). In Vivo Association of Ku With Mammalian Origins of DNA Replication. Mol. Biol. Cell. 12 (11), 3386-3401. doi: 10.1091/mbc.12.11.3386

Nowsheen, S., and Yang, E. S. (2012). The Intersection Between DNA Damage Response and Cell Death Pathways. Exp. Oncol. 34, 243-254.

Nussenzweig, A., Chen, C., Da Costa Soares, V., Sanchez, M., Sokol, K., Nussenzweig, M. C., et al. (1996). Requirement for Ku80 in Growth and Immunoglobulin V(D)J Recombination. Nature 382, 551-555. doi: 10.1038/ $382551 \mathrm{a} 0$

Ono, M., Tucker, P. W., and Capra, J. D. (1996). Ku Is a General Inhibitor of DNA-Protein Complex Formation and Transcription. Mol. Immunol. 33, 787796. doi: 10.1016/0161-5890(96)00030-2

Paludan, S. R., and Bowie, A. G. (2013). Immune Sensing of DNA. Immunity 38, 870-880. doi: 10.1016/j.immuni.2013.05.004

Park, S.-J., Ciccone, S. L. M., Freie, B., Kurimasa, A., Chen, D. J., Li, G. C., et al. (2004). A Positive Role for the Ku Complex in DNA Replication Following Strand Break Damage in Mammals*. J. Biol. Chem. 279, 6046-6055. doi: 10.1074/jbc.M311054200

Passos, D. O., Li, M., Yang, R., Rebensburg, S. V., Ghirlando, R., Jeon, Y., et al. (2017). Cryo-EM Structures and Atomic Model of the HIV-1 Strand Transfer Complex Intasome. Sci. (New York NY) 355, 89-92. doi: 10.1126/ science.aah5163

Peters, N. E., Ferguson, B. J., Mazzon, M., Fahy, A. S., Krysztofinska, E., ArribasBosacoma, R., et al. (2013). A Mechanism for the Inhibition of DNA-PKMediated DNA Sensing by a Virus. PLoS Pathog. 9, e1003649. doi: 10.1371/ journal.ppat.1003649

Peterson, S. E., Stellwagen, A. E., Diede, S. J., Singer, M. S., Haimberger, Z. W., Johnson, C. O., et al. (2001). The Function of a Stem-Loop in Telomerase RNA Is Linked to the DNA Repair Protein Ku. Nat. Genet. 27, 64-67. doi: 10.1038/83778

Pfingsten, J. S., Goodrich, K. J., Taabazuing, C., Ouenzar, F., Chartrand, P., and Cech, T. R. (2012). Mutually Exclusive Binding of Telomerase RNA and DNA by Ku Alters Telomerase Recruitment Model. Cell 148, 922-932. doi: 10.1016/ j.cell.2012.01.033

Pichlmair, A., and Reis e Sousa, C. (2007). Innate Recognition of Viruses. Immunity 27, 370-383. doi: 10.1016/j.immuni.2007.08.012

Radhakrishnan, S. K., Jette, N., and Lees-Miller, S. P. (2014). Non-Homologous End Joining: Emerging Themes and Unanswered Questions. DNA Repair 17, 2-8. doi: 10.1016/j.dnarep.2014.01.009
Rampakakis, E., Di Paola, D., and Zannis-Hadjopoulos, M. (2008). Ku Is Involved in Cell Growth, DNA Replication and G1-S Transition. J. Cell Sci. 121, 590600. doi: $10.1242 /$ jcs. 021352

Ribes-Zamora, A., Mihalek, I., Lichtarge, O., and Bertuch, A. A. (2007). Distinct Faces of the Ku Heterodimer Mediate DNA Repair and Telomeric Functions. Nat. Struct. Mol. Biol. 14, 301-307. doi: 10.1038/nsmb1214

Rice, G. I., Bond, J., Asipu, A., Brunette, R. L., Manfield, I. W., Carr, I. M., et al. (2009). Mutations Involved in Aicardi-Goutières Syndrome Implicate SAMHD1 as Regulator of the Innate Immune Response. Nat. Genet. 41, 829-832. doi: $10.1038 / n g .373$

Rivera-Calzada, A., Spagnolo, L., Pearl, L. H., and Llorca, O. (2007). Structural Model of Full-Length Human Ku70-Ku80 Heterodimer and Its Recognition of DNA and DNA-PKcs. EMBO Rep. 8, 56-62. doi: 10.1038/sj.embor.7400847

Roger, T., Lugrin, J., Le Roy, D., Goy, G., Mombelli, M., Koessler, T., et al. (2011). Histone Deacetylase Inhibitors Impair Innate Immune Responses to Toll-Like Receptor Agonists and to Infection. Blood 117, 1205-1217. doi: 10.1182/blood2010-05-284711

Rouse, J., and Jackson, S. P. (2002). Interfaces Between the Detection, Signaling, and Repair of DNA Damage. Science 297 (5581), 547-551. doi: 10.1126/ science. 1074740

Roy, A., Ghosh, A., Kumar, B., and Chandran, B. (2019). IFI16, a Nuclear Innate Immune DNA Sensor, Mediates Epigenetic Silencing of Herpesvirus Genomes by Its Association With H3K9 Methyltransferases SUV39H1 and GLP. eLife 8, e49500. doi: 10.7554/eLife.49500

Sánchez, A., and Russell, P. (2015). Ku Stabilizes Replication Forks in the Absence of Brc1. PLoS One 10 (5), e0126598. doi: 10.1371/journal.pone.0126598

Santos, S., Obukhov, Y., Nekhai, S., Bukrinsky, M., and Iordanskiy, S. (2012). Virus-Producing Cells Determine the Host Protein Profiles of HIV-1 Virion Cores. Retrovirology 9, 65. doi: 10.1186/1742-4690-9-65

Satoh, M., Wang, J., and Reeves, W. H. (1995). Role of Free P70 (Ku) Subunit in Posttranslational Stabilization of Newly Synthesized P80 During DNADependent Protein Kinase Assembly. Eur. J. Cell Biol. 66, 127-135.

Sawada, M., Sun, W., Hayes, P., Leskov, K., Boothman, D. A., and Matsuyama, S. (2003). Ku70 Suppresses the Apoptotic Translocation of Bax to Mitochondria. Nat. Cell Biol. 5, 320-329. doi: 10.1038/ncb950

Schild-Poulter, C., Matheos, D., Novac, O., Cui, B., Giffin, W., Ruiz, M. T., et al. (2003). Differential DNA Binding of Ku Antigen Determines Its Involvement in DNA Replication. DNA Cell Biol. 22, 65-78. doi: 10.1089/ 104454903321515887

Schweitzer, C. J., Jagadish, T., Haverland, N., Ciborowski, P., and Belshan, M. (2013). Proteomic Analysis of Early HIV-1 Nucleoprotein Complexes. J. Proteome Res. 12, 559-572. doi: 10.1021/pr300869h

Scully, R., Panday, A., Elango, R., and Willis, N. A. (2019). DNA Double-Strand Break Repair-Pathway Choice in Somatic Mammalian Cells. Nat. Rev. Mol. Cell Biol. 20, 698-714. doi: 10.1038/s41580-019-0152-0

Scutts, S. R., Ember, S. W., Ren, H., Ye, C., Lovejoy, C. A., Mazzon, M., et al. (2018). DNA-PK Is Targeted by Multiple Vaccinia Virus Proteins to Inhibit DNA Sensing. Cell Rep. 25, 1953-1965.e1954. doi: 10.1016/j.celrep.2018.10.034

Shadrina, O., Garanina, I., Korolev, S., Zatsepin, T., Van Assche, J., Daouad, F. et al. (2020). Analysis of RNA Binding Properties of Human Ku Protein Reveals Its Interactions With 7SK snRNA and Protein Components of 7SK snRNP Complex. Biochimie 171-172, 110-123. doi: 10.1016/j.biochi.2020. 02.016

Shadrina, O. A., Knyazhanskaya, E. S., Korolev, S. P., and Gottikh, M. B. (2016). Host Proteins Ku and HMGA1 As Participants of HIV-1 Transcription. Acta Naturae 8, 34-47. doi: 10.32607/20758251-2016-8-1-34-47

Shao, R.-G., Cao, C.-X., Zhang, H., Kohn, K. W., Wold, M. S., and Pommier, Y. (1999). Replication-Mediated DNA Damage by Camptothecin Induces Phosphorylation of RPA by DNA-Dependent Protein Kinase and Dissociates RPA: DNA-PK Complexes. Embo J. 18 (5), 1397-1406. doi: 10.1093/emboj/ 18.5.1397

Shao, Z., Flynn, R. A., Crowe, J. L., Zhu, Y., Liang, J., Jiang, W., et al. (2020). DNAPKcs has KU-Dependent Function in rRNA Processing and Haematopoiesis. Nature 579, 291-296. doi: 10.1038/s41586-020-2041-2

Sharma, S., and Fitzgerald, K. A. (2011). Innate Immune Sensing of DNA. PLoS Pathog. 7, e1001310. doi: 10.1371/journal.ppat.1001310

Shay, J. W., and Wright, W. E. (2019). Telomeres and Telomerase: Three Decades of Progress. Nat. Rev. Genet. 20, 299-309. doi: 10.1038/s41576-019-0099-1 
Singleton, B. K., Priestley, A., Steingrimsdottir, H., Gell, D., Blunt, T., Jackson, S. P., et al. (1997). Molecular and Biochemical Characterization of Xrs Mutants Defective in Ku80. Mol. Cell Biol. 17, 1264-1273. doi: 10.1128/MCB.17.3.1264

Singleton, B. K., Torres-Arzayus, M. I., Rottinghaus, S. T., Taccioli, G. E., and Jeggo, P. A. (1999). The C Terminus of Ku80 Activates the DNA-Dependent Protein Kinase Catalytic Subunit. Mol. Cell. Biol. 19 (5), 3267-3277. doi: 10.1128/MCB.19.5.3267

Spann, K. M., Tran, K.-C., Chi, B., Rabin, R. L., and Collins, P. L. (2004). Suppression of the Induction of Alpha, Beta, and Gamma Interferons by the NS1 and NS2 Proteins of Human Respiratory Syncytial Virus in Human Epithelial Cells and Macrophages. J. Virol. 78, 4363-4369. doi: 10.1128/ JVI.78.8.4363-4369.2004

Stellwagen, A. E., Haimberger, Z. W., Veatch, J. R., and Gottschling, D. E. (2003). $\mathrm{Ku}$ Interacts With Telomerase RNA to Promote Telomere Addition at Native and Broken Chromosome Ends. Genes Dev. 17 (19), 2384-2395. doi: 10.1101/ gad. 1125903

Studamire, B., and Goff, S. P. (2008). Host Proteins Interacting With the Moloney Murine Leukemia Virus Integrase: Multiple Transcriptional Regulators and Chromatin Binding Factors. Retrovirology 5, 48. doi: 10.1186/1742-4690-5-48

Subramanian, C., Hada, M., Opipari, A. W., Castle, V. P., and Kwok, R. P. S. (2013). CREB-Binding Protein Regulates Ku70 Acetylation in Response to Ionization Radiation in Neuroblastoma. Mol. Cancer Res. 11, 173. doi: 10.1158/ 1541-7786.MCR-12-0065

Subramanian, C., Opipari, A. W., Bian, X., Castle, V. P., and Kwok, R. P. S. (2005). Ku70 Acetylation Mediates Neuroblastoma Cell Death Induced by Histone Deacetylase Inhibitors. Proc. Natl. Acad. Sci. U. S. A. 102, 4842. doi: 10.1073/ pnas.0408351102

Sui, H., Chen, Q., and Imamichi, T. (2021). Cytoplasmic-Translocated Ku70 Senses Intracellular DNA and Mediates Interferon-Lambdal Induction. Immunology 163, 323-337. doi: 10.1111/imm.13318

Sui, J., Zhang, S., and Chen, B. P. C. (2020). DNA-dependent Protein Kinase in Telomere Maintenance and Protection. Cell. Mol. Biol. Lett. 25, 2. doi: 10.1186/ s11658-020-0199-0

Sui, H., Zhou, M., Imamichi, H., Jiao, X., Sherman, B. T., Lane, H. C., et al. (2017). STING Is an Essential Mediator of the Ku70-Mediated Production of IFN- $\lambda 1$ in Response to Exogenous DNA. Sci. Signal. 10 (488), 1-11. doi: 10.1126/ scisignal.aah5054

Sun, H., Huang, Y., Mei, S., Xu, F., Liu, X., Zhao, F., et al. (2021). A Nuclear Export Signal Is Required for cGAS to Sense Cytosolic DNA. Cell Rep. 34, 108586. doi: 10.1016/j.celrep.2020.108586

Sun, L., Wu, J., Du, F., Chen, X. G., and Chen, Z. J. (2013). Cyclic GMP-AMP Synthase Is a Cytosolic DNA Sensor That Activates the Type I Interferon Pathway. Science 339, 786-791. doi: 10.1126/science.1232458

Su, C., Zhan, G., and Zheng, C. (2016). Evasion of Host Antiviral Innate Immunity by HSV-1, an Update. Virol. J. 13, 38. doi: 10.1186/s12985-016-0495-5

Suzuki, R., Shindo, H., Tase, A., Kikuchi, Y., Shimizu, M., and Yamazaki, T. (2009). Solution Structures and DNA Binding Properties of the N-Terminal SAP Domains of SUMO E3 Ligases From Saccharomyces Cerevisiae and Oryza Sativa. Proteins 75 (2), 336-347. doi: 10.1002/prot.22243

Syedbasha, M., and Egli, A. (2017). Interferon Lambda: Modulating Immunity in Infectious Diseases. Front. Immunol. 8, 119. doi: 10.3389/fimmu.2017.00119

Takaoka, A. (2007). DAI (DLM-1/ZBP1) Is a Cytosolic DNA Sensor and an Activator of Innate Immune Response. Nature 448, 501-505. doi: 10.1038/ nature 06013

Takeuchi, O., and Akira, S. (2009). Innate Immunity to Virus Infection. Immunol. Rev. 227, 75-86. doi: 10.1111/j.1600-065X.2008.00737.x

Teixeira-Silva, A., Ait Saada, A., Hardy, J., Iraqui, I., Nocente, M. C., Fréon, K., et al. (2017). The End-Joining Factor Ku Acts in the End-Resection of Double Strand Break-Free Arrested Replication Forks. Nat. Commun. 8, 1982. doi: 10.1038/s41467-017-02144-5

Thapar, R., Wang, J. L., Hammel, M., Ye, R., Liang, K., Sun, C., et al. (2020). Mechanism of Efficient Double-Strand Break Repair by a Long Non-Coding RNA. Nucleic Acids Res. 48, 10953-10972. doi: 10.1093/nar/gkaa784

Thompson, M. R., Kaminski, J. J., Kurt-Jones, E. A., and Fitzgerald, K. A. (2011). Pattern Recognition Receptors and the Innate Immune Response to Viral Infection. Viruses 3, 920-940. doi: 10.3390/v3060920

Thompson, M. R., Sharma, S., Atianand, M., Jensen, S. B., Carpenter, S., Knipe, D. M., et al. (2014). Interferon $\gamma$-Inducible Protein (IFI) 16 Transcriptionally
Regulates Type I Interferons and Other Interferon-Stimulated Genes and Controls the Interferon Response to Both DNA and RNA Viruses. J. Biol. Chem. 289, 23568-23581. doi: 10.1074/jbc.M114.554147

Ting, N. S. Y., Yu, Y., Pohorelic, B., Lees-Miller, S. P., and Beattie, T. L. (2005). Human Ku70/80 Interacts Directly With hTR, the RNA Component of Human Telomerase. Nucleic Acids Res. 33, 2090-2098. doi: 10.1093/nar/gki342

Tintori, C., Brai, A., Fallacara, A. L., Fazi, R., Schenone, S., and Botta, M. (2014). Protein-protein Interactions and Human Cellular Cofactors as New Targets for HIV Therapy. Curr. Opin. Pharmacol. 18, 1-8. doi: 10.1016/ j.coph.2014.06.005

Tyagi, S., Ochem, A., and Tyagi, M. (2011). DNA-Dependent Protein Kinase Interacts Functionally With the RNA Polymerase II Complex Recruited at the Human Immunodeficiency Virus (HIV) Long Terminal Repeat and Plays an Important Role in HIV Gene Expression. J. Gen. Virol. 92 (Pt 7), 1710-1720. doi: 10.1099/vir.0.029587-0

Unterholzner, L., and Bowie, A. G. (2011). Innate DNA Sensing Moves to the Nucleus. Cell Host Microbe 9, 351-353. doi: 10.1016/j.chom.2011.05.001

Unterholzner, L., Keating, S. E., Baran, M., Horan, K. A., Jensen, S. B., Sharma, S., et al. (2010). IFI16 Is an Innate Immune Sensor for Intracellular DNA. Nat. Immunol. 11, 997-1004. doi: 10.1038/ni.1932

Uzé, G., and Monneron, D. (2007). IL-28 and IL-29: Newcomers to the Interferon Family. Biochimie 89, 729-734. doi: 10.1016/j.biochi.2007.01.008

Vincent, K. A., York-Higgins, D., Quiroga, M., and Brown, P. O. (1990). Host Sequences Flanking the HIV Provirus. Nucleic Acids Res. 18, 6045-6047. doi: 10.1093/nar/18.20.6045

Vink, C., Groenink, M., Elgersma, Y., Fouchier, R. A., Tersmette, M., and Plasterk, R. H. (1990). Analysis of the Junctions Between Human Immunodeficiency Virus Type 1 Proviral DNA and Human DNA. J. Virol. 64, 5626-5627. doi: 10.1128/jvi.64.11.5626-5627.1990

Walker, J. R., Corpina, R. A., and Goldberg, J. (2001). Structure of the Ku Heterodimer Bound to DNA and Its Implications for Double-Strand Break Repair. Nature 412, 607-614. doi: 10.1038/35088000

Wang, Y., Cortez, D., Yazdi, P., Neff, N., Elledge, S. J., and Qin, J. (2000). BASC, a Super Complex of BRCA1-Associated Proteins Involved in the Recognition and Repair of Aberrant DNA Structures. Genes Dev. 14, 927-939.

Wang, Y., Fu, Z., Li, X., Liang, Y., Pei, S., Hao, S., et al. (2021). Cytoplasmic DNA Sensing by KU Complex in Aged CD4+ T Cell Potentiates T Cell Activation and Aging-Related Autoimmune Inflammation. Immunity 54 (4), 632647.e639. doi: 10.1016/j.immuni.2021.02.003

Wang, J., Kang, L., Song, D., Liu, L., Yang, S., Ma, L., et al. (2017). Ku70 Senses HTLV-1 DNA and Modulates HTLV-1 Replication. J. Immunol. 199, $2475-$ 2482. doi: 10.4049/jimmunol.1700111

Wang, K., Ni, L., Wang, S., Zheng, C., and Hutt-Fletcher, L. (2014). Herpes Simplex Virus 1 Protein Kinase US3 Hyperphosphorylates P65/RelA and Dampens NF- $\mathrm{B}$ Activation. J. Virol. 88 (14), 7941-7951. doi: 10.1128/ JVI.03394-13

Wang, S., Wang, K., Lin, R., and Zheng, C. (2013). Herpes Simplex Virus 1 Serine/ Threonine Kinase US3 Hyperphosphorylates IRF3 and Inhibits Beta Interferon Production. J. Virol. 87 (23), 12814-12827. doi: 10.1128/JVI.02355-13

Waninger, S., Kuhen, K., Hu, X., Chatterton, J. E., Wong-Staal, F., and Tang, H. (2004). Identification of Cellular Cofactors for Human Immunodeficiency Virus Replication via a Ribozyme-Based Genomics Approach. J. Virol. 78 (23), 12829-12837. doi: 10.1128/JVI.78.23.12829-12837.2004

Weterings, E., Gallegos, A. C., Dominick, L. N., Cooke, L. S., Bartels, T. N., Vagner, J., et al. (2016). A Novel Small Molecule Inhibitor of the DNA Repair Protein Ku70/80. DNA Repair 43, 98-106. doi: 10.1016/j.dnarep.2016.03.014

Wood, A. M., Laster, K., Rice, E. L., and Kosak, S. T. (2015). A Beginning of the End: New Insights Into the Functional Organization of Telomeres. Nucleus 6, 172-178. doi: 10.1080/19491034.2015.1048407

Xia, P., Wang, S., Gao, P., Gao, G., and Fan, Z. (2016). DNA Sensor cGAS-Mediated Immune Recognition. Protein Cell 7 (11), 777-791. doi: 10.1007/s13238-016-0320-3

Xing, J., Ni, L., Wang, S., Wang, K., Lin, R., and Zheng, C. (2013). Herpes Simplex Virus 1-Encoded Tegument Protein VP16 Abrogates the Production of Beta Interferon (IFN) by Inhibiting NF- $\kappa \mathrm{B}$ Activation and Blocking IFN Regulatory Factor 3 To Recruit Its Coactivator CBP. J. Virol. 87 (17), 9788-9801. doi: 10.1128/JVI.01440-13

Yaneva, M., Kowalewski, T., and Lieber, M. R. (1997). Interaction of DNADependent Protein Kinase With DNA and With Ku: Biochemical and Atomic- 
Force Microscopy Studies. EMBO J. 16, 5098-5112. doi: 10.1093/emboj/ 16.16.5098

Yang, P., An, H., Liu, X., Wen, M., Zheng, Y., Rui, Y., et al. (2010). The Cytosolic Nucleic Acid Sensor LRRFIP1 Mediates the Production of Type I Interferon via a [Beta]-Catenin-Dependent Pathway. Nat. Immunol. 11, 487-494. doi: 10.1038/ni.1876

Yoneyama, M., and Fujita, T. (2008). Structural Mechanism of RNA Recognition by the RIG-I-Like Receptors. Immunity 29, 178-181. doi: 10.1016/ j.immuni.2008.07.009

Yoneyama, M., and Fujita, T. (2009). RNA Recognition and Signal Transduction by RIG-I-Like Receptors. Immunol. Rev. 227, 54-65. doi: 10.1111/j.1600065X.2008.00727.x

Yoneyama, M., and Fujita, T. (2010). Recognition of Viral Nucleic Acids in Innate Immunity. Rev. Med. Virol. 20 (1), 4-22. doi: 10.1002/rmv.633

Yoo, S., and Dynan, W. S. (1998). Characterization of the RNA Binding Properties of Ku Protein. Biochemistry 37, 1336-1343. doi: 10.1021/bi972100w

Yoo, S., Kimzey, A., and Dynan, W. S. (1999). Photocross-Linking of an Oriented DNA Repair Complex: Ku BOUND AT A SINGLE DNA END*. J. Biol. Chem. 274, 20034-20039. doi: 10.1074/jbc.274.28.20034

Zhang, X., Brann, T. W., Zhou, M., Yang, J., Oguariri, R. M., Lidie, K. B., et al. (2011a). Cutting Edge: Ku70 Is a Novel Cytosolic DNA Sensor That Induces Type III Rather Than Type I IFN. J. Immunol. 186, 4541-4545. doi: 10.4049/ jimmunol.1003389

Zhang, Y., He, Q., Hu, Z., Feng, Y., Fan, L., Tang, Z., et al. (2016b). Long Noncoding RNA LINP1 Regulates Repair of DNA Double-Strand Breaks in Triple-Negative Breast Cancer. Nat. Struct. Mol. Biol. 23, 522-530. doi: 10.1038/nsmb.3211

Zhang, Z., Kim, T., Bao, M., Facchinetti, V., Jung, S. Y., Ghaffari, A. A., et al. (2011b). DDX1, DDX21, and DHX36 Helicases Form a Complex With the Adaptor Molecule TRIF to Sense dsRNA in Dendritic Cells. Immunity 34, 866878. doi: 10.1016/j.immuni.2011.03.027

Zhang, D., Su, C., Zheng, C., and Sandri-Goldin, R. M. (2016a). Herpes Simplex Virus 1 Serine Protease VP24 Blocks the DNA-Sensing Signal Pathway by Abrogating Activation of Interferon Regulatory Factor 3. J. Virol. 90 (12), 5824-5829. doi: 10.1128/JVI.00186-16
Zhang, Y., Yeruva, L., Marinov, A., Prantner, D., Wyrick, P. B., Lupashin, V., et al. (2014). The DNA Sensor, Cyclic GMP-AMP Synthase, Is Essential for Induction of IFN- $\beta$ During Chlamydia Trachomatis Infection. J. Immunol. 193, 2394-2404. doi: 10.4049/jimmunol.1302718

Zhang, Z., Yuan, B., Bao, M., Lu, N., Kim, T., and Liu, Y. (2011c). The Helicase DDX41 Senses Intracellular DNA Mediated by the Adaptor STING in Dendritic Cells. Nat. Immunol. 12, 959-965. doi: 10.1038/ni.2091

Zheng, Y., Ao, Z., Wang, B., Jayappa, K. D., and Yao, X. (2011). Host Protein Ku70 Binds and Protects HIV-1 Integrase From Proteasomal Degradation and Is Required for HIV Replication. J. Biol. Chem. 286, 17722-17735. doi: 10.1074/ jbc.M110.184739

Zhou, B.-B. S., and Elledge, S. J. (2000). The DNA Damage Response: Putting Checkpoints in Perspective. Nature 408, 433-439. doi: 10.1038/35044005

Author Disclaimer: The content of this publication does not necessarily reflect the views or policies of the Department of Health and Human Services, nor does mention of trade names, commercial products, or organizations imply endorsement by the U.S. Government.

Conflict of Interest: The authors declare that the research was conducted in the absence of any commercial or financial relationships that could be construed as a potential conflict of interest.

Publisher's Note: All claims expressed in this article are solely those of the authors and do not necessarily represent those of their affiliated organizations, or those of the publisher, the editors and the reviewers. Any product that may be evaluated in this article, or claim that may be made by its manufacturer, is not guaranteed or endorsed by the publisher.

Copyright (c) 2021 Sui, Hao, Chang and Imamichi. This is an open-access article distributed under the terms of the Creative Commons Attribution License (CC BY). The use, distribution or reproduction in other forums is permitted, provided the original author(s) and the copyright owner(s) are credited and that the original publication in this journal is cited, in accordance with accepted academic practice. No use, distribution or reproduction is permitted which does not comply with these terms. 